\title{
Identification of candidate genes involved in early iron deficiency chlorosis signaling in soybean (Glycine max) roots and leaves
}

Adrienne N Moran Lauter ${ }^{1}$, Gregory A Peiffer ${ }^{1}$, Tengfei Yin², Steven A Whitham³ ${ }^{3}$ Dianne Cook², Randy C Shoemaker ${ }^{1,4}$ and Michelle A Graham ${ }^{1,4^{*}}$

\begin{abstract}
Background: Iron is an essential micronutrient for all living things, required in plants for photosynthesis, respiration and metabolism. A lack of bioavailable iron in soil leads to iron deficiency chlorosis (IDC), causing a reduction in photosynthesis and interveinal yellowing of leaves. Soybeans (Glycine max (L.) Merr.) grown in high pH soils often suffer from IDC, resulting in substantial yield losses. Iron efficient soybean cultivars maintain photosynthesis and have higher yields under IDC-promoting conditions than inefficient cultivars.
\end{abstract}

Results: To capture signaling between roots and leaves and identify genes acting early in the iron efficient cultivar Clark, we conducted a RNA-Seq study at one and six hours after replacing iron sufficient hydroponic media (100 $\mu \mathrm{M}$ iron(III) nitrate nonahydrate) with iron deficient media (50 $\mathrm{MM}$ iron(III) nitrate nonahydrate). At one hour of iron stress, few genes were differentially expressed in leaves but many were already changing expression in roots. By six hours, more genes were differentially expressed in the leaves, and a massive shift was observed in the direction of gene expression in both roots and leaves. Further, there was little overlap in differentially expressed genes identified in each tissue and time point.

Conclusions: Genes involved in hormone signaling, regulation of DNA replication and iron uptake utilization are key aspects of the early iron-efficiency response. We observed dynamic gene expression differences between roots and leaves, suggesting the involvement of many transcription factors in eliciting rapid changes in gene expression. In roots, genes involved iron uptake and development of Casparian strips were induced one hour after iron stress. In leaves, genes involved in DNA replication and sugar signaling responded to iron deficiency. The differentially expressed genes (DEGs) and signaling components identified here represent new targets for soybean improvement.

Keywords: Iron deficiency chlorosis, Soybean, Glycine max, RNA-Seq

\section{Background}

Iron is an important micronutrient for all living things. In plants, it is essential for photosynthesis, respiration and other metabolic processes. Plants adjust their iron uptake from the soil to achieve the proper cellular iron concentrations. Without enough iron, plants suffer Iron Deficiency Chlorosis (IDC), which is among the most common and potentially severe nutritional stresses in plants [1]. IDC is typically not due to low amounts of

\footnotetext{
* Correspondence: michelle.graham@ars.usda.gov

'USDA-Agricultural Research Service, Corn Insects and Crop Genetics Research Unit, 1565 Agronomy Hall, Ames, IA 50011, USA

${ }^{4}$ Department of Agronomy, lowa State University, Ames, lowa 50011, USA Full list of author information is available at the end of the article
}

iron in the soil, but rather to an unusable ferric $\left(\mathrm{Fe}^{3+}\right)$ state. Too much iron is also problematic, as free iron leads to reactive oxygen species (ROS), DNA damage, and other cellular stress [2]. Therefore, iron homeostasis is tightly controlled by regulating iron uptake, transport and storage. IDC is a global problem, but is especially problematic in the calcareous soils of the Midwestern $\mathrm{U}$. S., where the majority of U.S. soybeans are grown [3]. Calcareous soil is identified by the presence of calcium carbonate (or lime) and a $\mathrm{pH}$ higher than 7 , which keeps iron in the ferric $\left(\mathrm{Fe}^{3+}\right)$ state. Many high yielding soybeans are susceptible to IDC, which results in a yellowing of leaves due to reduced photosynthesis. Symptoms

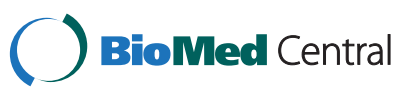

(c) 2014 Moran Lauter et al.; licensee BioMed Central Ltd. This is an Open Access article distributed under the terms of the Creative Commons Attribution License (http://creativecommons.org/licenses/by/4.0), which permits unrestricted use, distribution, and reproduction in any medium, provided the original work is properly credited. The Creative Commons Public Domain Dedication waiver (http://creativecommons.org/publicdomain/zero/1.0/) applies to the data made available in this article, unless otherwise stated. 
vary in degree of severity, but can result in total yield loss. The recommended management for IDC is growing IDCresistant soybean lines. However, resistant lines yield lower than susceptible lines in conditions that do not favor the development of IDC. Identifying the genetic basis of IDC resistance may aid in the development of IDC tolerant lines that perform well in multiple soil types.

Plants have two mechanisms for acquiring iron from the soil (Strategy I and II). Strategy I, which occurs in most dicots including soybean, functions through the induction of the Fe-deficiency Induced Transcription Factor (FIT) in the root, which regulates Ferric-chelate Reductase (FRO) and Iron-Regulated Transporter (IRT) [4-6]. While these genes are activated in the root, it is believed that the signal activating these genes comes from an unknown factor that originates in the leaves $[7,8]$. Hormones are obvious candidates for controlling signaling from the shoot to the root. Garcia et al. [9] demonstrated that the hormones ethylene and nitric oxide act early in response to IDC in the roots and are necessary for the induction of iron uptake genes. Thus far, the study of ethylene and nitric oxide function has been limited to the roots. Examining the gene expression in multiple tissues during IDC response may allow for the construction of a complete signaling pathway.

In the early 1970's, near isogenic soybean lines (NILs), Clark (PI54833) and Isoclark, were developed that differ in their responses to iron stress [10]. The cultivar Clark (PI54833) is iron efficient and does not develop IDC symptoms in iron-limiting conditions. Isoclark is susceptible to iron stress and develops interveinal chlorosis in response to iron limitation. Gene expression comparisons between Clark and Isoclark, which share 98\% genetic identity, have allowed the identification of hundreds of genes involved in iron stress responses in soybean. In the last several years, microarray analyses, RNA-Seq, introgression and association mapping, sub-NIL development and virus-induced gene silencing (VIGS) have been used to identify and characterize soybean genes that are differentially expressed during iron stress and iron stress recovery [11-15]. However, the early signaling events in the iron efficiency stress response remain elusive. Therefore, the work presented here aims to capture early transcriptional responses to iron stress in the iron efficient line Clark. We have used RNA-Seq to measure transcriptional responses one and six hours after iron stress. The differentially expressed genes (DEGs) and signaling components identified here represent new targets for soybean improvement.

\section{Results}

RNA-Seq reveals a dynamic change in gene expression in response to IDC

In order to identify early responses to iron stress, we quantified expression of genes at one and six hours post iron stress in leaves and roots of the iron efficient line Clark. While other studies have used both Clark and Isoclark, previous work [13] has demonstrated that Isoclark is iron inefficient and does not induce expression of genes involved in iron homeostasis in response to iron stress. Therefore, we limited our study to Clark. To induce iron stress, the roots of plants grown in ironsufficient $(100 \mu \mathrm{M} \mathrm{Fe}(\mathrm{NO} 3) 3 \cdot 9 \mathrm{H} 2 \mathrm{O})$ conditions for sixteen days were rinsed in distilled water and then plants were transferred into either iron-sufficient $(100 \mu \mathrm{M} \mathrm{Fe}$ (NO3)3•9H2O) or iron-deficient $(50 \mu \mathrm{M} \mathrm{Fe}(\mathrm{NO} 3) 3 \cdot 9 \mathrm{H} 2 \mathrm{O})$ conditions. Two replicates of root and 1st trifoliate leaf tissues were collected at one and six hours after transfer to sufficient or insufficient conditions for a total of eight sample types. Following RNA isolation, samples were sent to the National Center for Genomic Research for single-end RNA sequencing on an Illumina Genome Analyzer II with a read length of $36 \mathrm{bp}$. Following the bioinformatic pipeline detailed in the Materials and Methods, a total of 507,784,149 reads $(252,907,004$ from 8 leaf samples, 254,877,145 from 8 root samples) were mapped to the soybean genome (G. max version $1.1[16])$. The Illumina reads generated by this study were deposited in the National Center for Biotechnology Short Read Archive (NCBI SRA Bioproject accession SRP031889).

To identify genes differentially expressed in response to iron stress in each sample, we used the edgeR [17] statistical package comparing deficient and sufficient replicates at a given time point and tissue. Most RNASeq analysis tools provide a list of DEGs and report average expression across replicates. However, one bad replicate can extremely bias which genes are identified as differentially expressed and the level and direction of expression. Therefore, it is important to use statistical packages that report expression of all replicates and use visualization tools of raw and normalized data to verify biological and technical reproducibility of replicates. This step is particularly important in experiments such as ours, where only two replicates were used. We used the package ggplot2 (CRAN, [18]) to compare normalized gene expression in replicate data sets. In addition, ggplot2 was used to create porcupine plots [19] of significantly differentially expressed genes at multiple False Discovery Rates (FDR) (Figure 1, Additional file 1) relative to the expression of all genes. The porcupine plots use lines to connect replicate data points, allowing visual identification of any problematic data. Following these analyses, genes were considered significant if they had a fold change $>2.0$ (deficient/sufficient) and a false discovery rate $(\mathrm{FDR})<0.05$. The DEGs were annotated using the SoyBase Genome Annotation Report page (http:// soybase.org/genomeannotation/index.php), which provided UniRef100 [20] hit information, best $A$. thaliana 


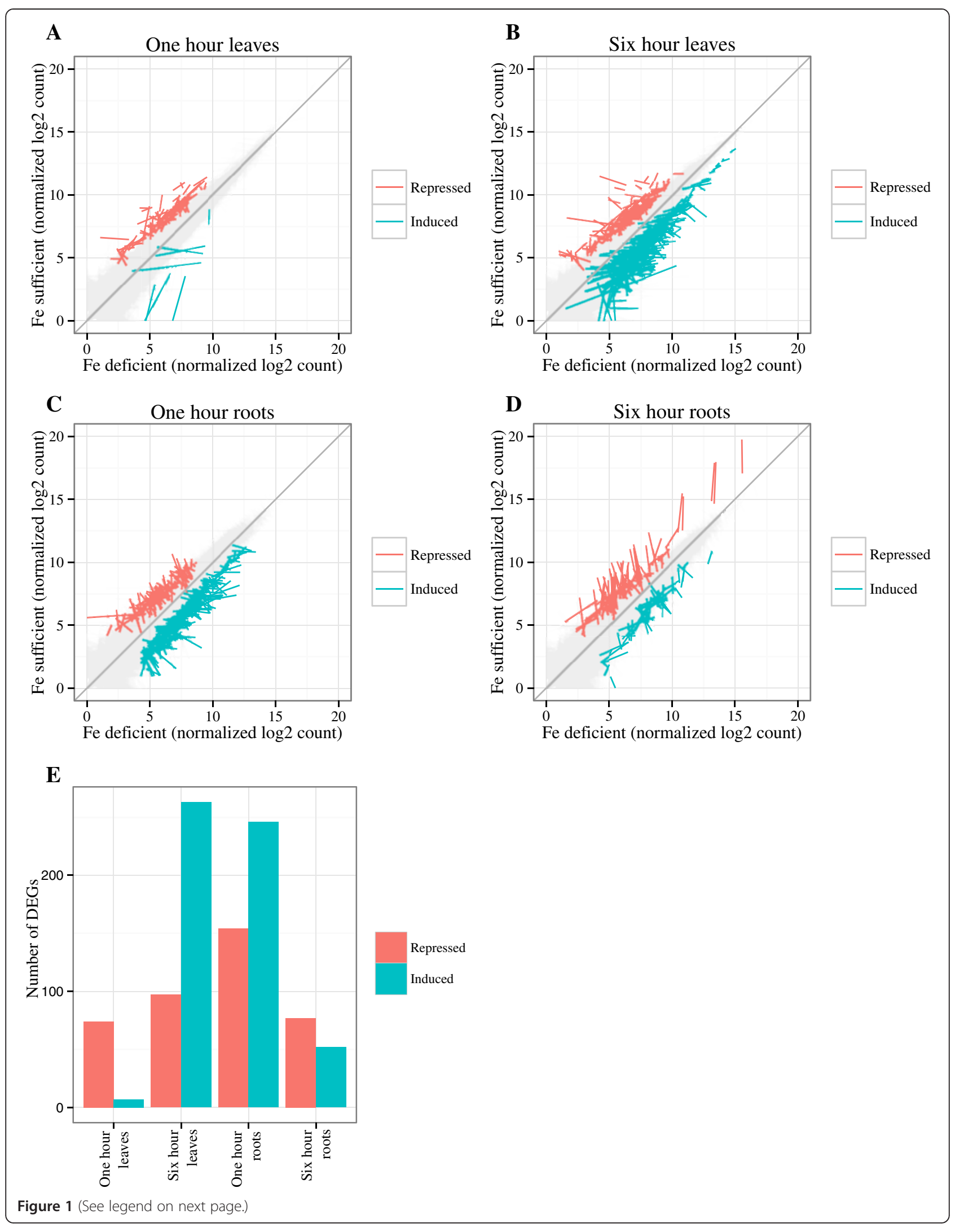


(See figure on previous page.)

Figure 1 Genes significantly differentially expressed in response to iron stress. Significantly differentially expressed genes (DEGs) (FDR < 0.05) were identified by comparing gene expression in iron deficient conditions to iron sufficient conditions (D/S). Porcupine plots were used to visualize the expression of all genes and all DEGs. Expression of all genes is shown in grey. Expression of DEGs is shown in red (repressed by iron deficiency) and blue (induced by iron deficiency). A line joins replicates of DEGs. A. DEGs from leaves after one hour of iron stress. B. DEGs from leaves after six hours of iron stress. $\mathbf{C}$. DEGs from roots after one hour of iron stress. D. DEGs from roots after six hours of iron stress. $\mathbf{E}$. Bar graph of the total number of repressed or induced differentially expressed genes at each tissue and time point.

homologs and gene ontology information inferred from $A$. thaliana (The Arabidopsis Information Resource [TAIR] version 10, www.arabidopsis.org). The DEGs and their annotations are provided for each tissue and time point (Additional files 2, 3, 4 and 5).

We identified 81 and 400 DEGs in response to iron stress in one hour and six hour leaves, respectively, and 360 and 129 DEGs were identified in one hour and six hour roots (Figure 1). Surprisingly, there was little overlap in the DEGs identified within the same tissue at different time points or across tissues at the same time point. Only seven genes were in common between one and six hour leaves, and another four genes were in common between one and six hour roots (Additional files 2, 3, 4 and 5). For nine of these eleven genes, the direction of expression changed between the one hour and six hour time points. Similarly, only eleven genes were in common between roots and leaves, regardless of time point. The small degree of overlap in DEGs across sample types accompanied by large changes in expression levels between time points suggests dynamic and distinct responses to iron stress occur in leaves and roots.

To develop an understanding of which genes were affected by iron stress, we began focusing on the top ten induced and repressed genes in each sample, paying particular attention to those genes with homology to Arabidopsis genes with known roles in nutrient stress responses, growth and signaling (Table 1). In one hour leaves, iron deficiency led to decreased expression of 74 of the 81 DEGs. The seven genes induced by iron deficiency included homologs of previously described Arabidopsis genes AtPLP1 (Glyma07g13790, 6E ${ }^{-89}$ ), AtGASA1 (Glyma14g40400, 4E $\mathrm{E}^{-32}$ ), AtSWEET12 (Glyma05g38351,

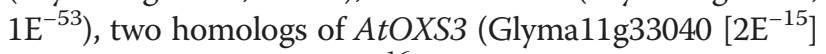
and Glyma18g05160 $\left.\left[6 \mathrm{E}^{-16}\right]\right)$ and a copper amine oxidase (Glyma01g07860 [E = 0]) (Table 1). AtPLP1 is patatinrelated phospholipase that is differentially expressed in response to phosphate stress [21]. AtGASA1 (GA-Stimulated in Arabidopsis) is a gibberellic acid-regulated protein and expressed in rosettes [22]. AtSWEET12 is a sucrose transporter involved in phloem loading that transfers sucrose from the leaves to nonphotosynthetic tissues elsewhere in the plant [23]. Overexpression of AtOXS3 in Arabidopsis resulted in greater tolerance to heavy metals and oxidative stress. Copper amine oxidase is upregulated in response to wounding in chickpea [24] and in response to nematode infection but not wounding, in Arabidopsis [25]. The top ten genes repressed by iron deficiency included two homologs of AtNIA1 (Glyma06g11430 [E=0] and Glyma13g02510 [E = 0]) and a homolog of AtDXR (Glyma16g10880, $\mathrm{E}=0)$. AtNIA is required for nitric oxide (NO) production [26]. NO acts an important signaling molecule for a variety of abiotic stresses including iron deficiency and drought [27]. AtDXR is localized to the chloroplast and catalyzes the first committed step of isoprenoid biosynthesis leading to the production of chlorophyll, carotenoids, ABA, brassinosteroids, cytokinins and gibberellins [28].

In one hour roots, 263 of the 360 DEGs were induced in response to iron stress. The top ten induced genes included two homologs of AtRCI3 (Glyma10g02730 [9E ${ }^{-120}$ ]

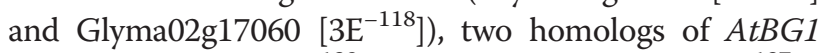

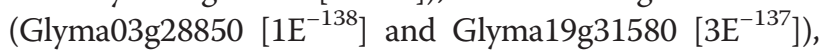

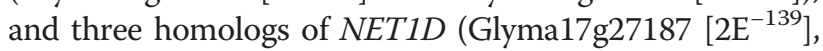

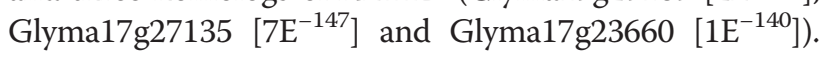
AtRCI3 (Rare Cold Inducible gene 3 ) is a peroxidase that is involved in salt-tolerance, dehydration and potassium deficiency signaling $[29,30]$. BG1 responds to a variety of biotic stresses in Arabidopsis [31]. NET1D is an actinbinding protein highly expressed in the stele and conducting tissues of the roots [32]. Genes repressed by iron deficiency included a homolog of 2OG-Fe(II)-dependent ox-

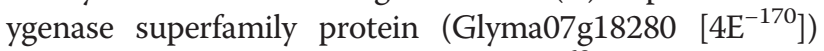

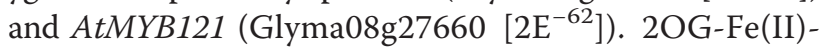
dependent oxygenase family members are involved in hormone synthesis in plants, particularly ethylene synthesis [33]. AtMYB121 responds to salinity stress in Arabidopsis roots [34].

Six hours after plants were transferred from iron sufficient to iron deficient media, iron deficiency induced the expression of 246 genes in leaves but repressed the expression of 154. Induced genes included a homolog

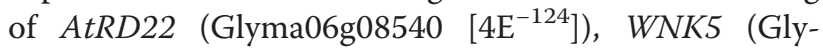
ma01g32450 $[\mathrm{E}=0]$ ) and two homologs of ASN1/ AtDIN6 (Glyma02g39320 [E =0] and Glyma11g27480 $[\mathrm{E}=0])$. Arabidopsis AtRD22 is responsive to abscisic acid, water and salt stress [35]. The rice homolog of WNK5 (with no lysine kinase), OsWNK1, has a suspected role in abiotic stress tolerance and is involved in circadian rhythm [36]. The wheat homolog of asparagine synthetase TaASN1 has been shown to be upregulated in roots in 
Table 1 Top ten significantly induced and repressed DEGs under iron stress at each time and tissue

\begin{tabular}{|c|c|c|c|}
\hline \multicolumn{4}{|l|}{ Leaf one hour } \\
\hline Glyma 1.1 ID & $\log _{2}$ fold change & TAIR10 annotation & E-value \\
\hline Glyma11g12650 & 5.00 & NA & NA \\
\hline Glyma07g13790 & 3.78 & PLP1, AtPLAIVA | Acyl transferase/hydrolase/lysophospholipase superfamily protein & $6.0 \mathrm{E}-89$ \\
\hline Glyma14g40400 & 3.37 & GASA1 | GAST1 protein homolog 1 & 4.0E-32 \\
\hline Glyma05g38351 & 3.06 & MTN3, SWEET12, AtSWEET12 | homolog of Medicago truncatula & $1.0 \mathrm{E}-53$ \\
\hline Glyma11g33040 & 2.83 & OXS3, ATOXS3 | oxidative stress 3 & $2.0 \mathrm{E}-15$ \\
\hline Glyma18g05160 & 2.59 & OXS3, ATOXS3 | oxidative stress 3 & $6.0 \mathrm{E}-16$ \\
\hline Glyma01g07860 & 1.28 & Copper amine oxidase family protein & $0.0 \mathrm{E}+00$ \\
\hline Glyma01g35620 & -4.38 & Long-chain fatty alcohol dehydrogenase family protein & $0.0 \mathrm{E}+00$ \\
\hline Glyma09g35210 & -4.05 & Long-chain fatty alcohol dehydrogenase family protein & $0.0 \mathrm{E}+00$ \\
\hline Glyma18g38410 & -4.05 & MuDR family transposase & $2.0 \mathrm{E}-44$ \\
\hline Glyma16g10880 & -3.78 & DXR, PDE129 | 1-deoxy-D-xylulose 5-phosphate reductoisomerase & $0.0 \mathrm{E}+00$ \\
\hline Glyma16g15790 & -3.61 & WEB1 | Plant protein of unknown function (DUF827) & 4.0E-170 \\
\hline Glyma13g02510 & -3.36 & NIA1, GNR1, NR1 | nitrate reductase 1 & $0.0 \mathrm{E}+00$ \\
\hline Glyma06g11430 & -3.24 & NIA1, GNR1, NR1 | nitrate reductase 1 & $0.0 \mathrm{E}+00$ \\
\hline Glyma13g39440 & -2.83 & CER4, G7, FAR3 | Jojoba acyl CoA reductase-related male sterility protein & $0.0 \mathrm{E}+00$ \\
\hline Glyma01g25890 & -2.80 & Major facilitator superfamily protein & $0.0 \mathrm{E}+00$ \\
\hline Glyma07g37380 & -2.77 & Protein phosphatase $2 \mathrm{C}$ family protein & 1.0E-164 \\
\hline \multicolumn{4}{|l|}{ Leaf six hours } \\
\hline Glyma 1.1 ID & $\log _{2}$ fold change & TAIR10 annotation & E-value \\
\hline Glyma15g18360 & 6.37 & XTR6, XTH23 | xyloglucan endotransglycosylase 6 & 3.0E-141 \\
\hline Glyma02g39320 & 5.94 & ASN1, DIN6, AT-ASN1 | glutamine-dependent asparagine synthase 1 & $0.0 \mathrm{E}+00$ \\
\hline Glyma03g37970 & 4.63 & ATGPAT2, GPAT2 | glycerol-3-phosphate acyltransferase 2 & $0.0 \mathrm{E}+00$ \\
\hline Glyma09g24170 & 4.18 & Heavy metal transport/detoxification superfamily protein & 2.0E-19 \\
\hline Glyma11g27480 & 3.81 & ASN1, DIN6, AT-ASN1 | glutamine-dependent asparagine synthase 1 & $0.0 \mathrm{E}+00$ \\
\hline Glyma06g08540 & 3.80 & RD22, ATRD22 | BURP domain-containing protein & 4.0E-124 \\
\hline Glyma08g45281 & 3.77 & NA & NA \\
\hline Glyma01g32450 & 3.70 & WNK5 | with no lysine (K) kinase 5 & $0.0 \mathrm{E}+00$ \\
\hline Glyma03g37990 & 3.61 & ATGPAT2, GPAT2 | glycerol-3-phosphate acyltransferase 2 & $0.0 \mathrm{E}+00$ \\
\hline Glyma16g21050 & 3.59 & ABCG14 | ATP-binding cassette 14 & $0.0 \mathrm{E}+00$ \\
\hline Glyma14g35340 & -5.53 & EXO | Phosphate-responsive 1 family protein & $2.0 \mathrm{E}-146$ \\
\hline Glyma14g35330 & -4.69 & EXO | Phosphate-responsive 1 family protein & $5.0 \mathrm{E}-158$ \\
\hline Glyma01g01500 & -4.47 & Mono-/di-acylglycerol lipase, N-terminal;Lipase, class 3 & 1.0E-80 \\
\hline Glyma01g01530 & -4.12 & Mono-/di-acylglycerol lipase, N-terminal;Lipase, class 3 & $1.0 \mathrm{E}-10$ \\
\hline Glyma11g03500 & -4.08 & Eukaryotic aspartyl protease family protein & 1.0E-170 \\
\hline Glyma13g33780 & -3.90 & NA & NA \\
\hline Glyma16g01430 & -3.59 & SAUR-like auxin-responsive protein family & $6.0 \mathrm{E}-37$ \\
\hline Glyma02g38200 & -3.58 & Octicosapeptide/Phox/Bem1p family protein & 2.0E-49 \\
\hline Glyma06g10710 & -3.35 & EXO | Phosphate-responsive 1 family protein & 9.0E-154 \\
\hline Glyma02g06810 & -3.33 & Unknown protein & $1.0 \mathrm{E}-37$ \\
\hline \multicolumn{4}{|l|}{ Root one hour } \\
\hline Glyma 1.1 ID & $\log _{2}$ fold change & TAIR10 annotation & E-value \\
\hline Glyma10g02730 & 4.85 & $\mathrm{RCl} 3, \mathrm{RCI} 3 \mathrm{~A}$ | Peroxidase superfamily protein & $9.0 \mathrm{E}-120$ \\
\hline Glyma17g27187 & 4.66 & Kinase interacting (KIP1-like) family protein (NET1D) & 2.0E-139 \\
\hline
\end{tabular}


Table 1 Top ten significantly induced and repressed DEGs under iron stress at each time and tissue (Continued)

\begin{tabular}{|c|c|c|c|}
\hline Glyma03g28850 & 3.90 & BG1 | beta-1,3-glucanase 1 & $1.0 \mathrm{E}-138$ \\
\hline Glyma02g17060 & 3.85 & $\mathrm{RCI} 3, \mathrm{RCI3A}$ | Peroxidase superfamily protein & $3.0 \mathrm{E}-118$ \\
\hline Glyma17g23660 & 3.77 & Kinase interacting (KIP1-like) family protein (NET1D) & $1.0 \mathrm{E}-140$ \\
\hline Glyma19g31580 & 3.67 & BG1 | beta-1,3-glucanase 1 & $3.0 \mathrm{E}-137$ \\
\hline Glyma15g12600 & 3.64 & Bifunctional inhibitor/lipid-transfer protein/seed storage $2 S$ albumin superfamily protein & $1.0 \mathrm{E}-35$ \\
\hline Glyma17g27135 & 3.61 & Kinase interacting (KIP1-like) family protein (NET1D) & 7.0E-147 \\
\hline Glyma03g02834 & 3.40 & NA & NA \\
\hline Glyma09g01680 & 3.16 & Bifunctional inhibitor/lipid-transfer protein/seed storage $2 S$ albumin superfamily protein & $2.0 \mathrm{E}-34$ \\
\hline Glyma05g02040 & -3.46 & NA & NA \\
\hline Glyma08g27660 & -3.25 & ATMYB121, MYB121 | myb domain protein 121 & $2.0 \mathrm{E}-62$ \\
\hline Glyma18g38410 & -2.86 & MuDR family transposase & $2.0 \mathrm{E}-44$ \\
\hline Glyma10g41670 & -2.83 & NA & NA \\
\hline Glyma11g05517 & -2.58 & NA & NA \\
\hline Glyma06g05990 & -2.50 & Protein kinase superfamily protein & $0.0 \mathrm{E}+00$ \\
\hline Glyma10g28850 & -2.35 & Unknown protein & $1.0 \mathrm{E}-48$ \\
\hline Glyma07g18280 & -2.30 & 2-oxoglutarate (2OG) and Fe(II)-dependent oxygenase superfamily protein & 4.0E-170 \\
\hline Glyma20g23020 & -2.27 & Unknown protein & $1.0 \mathrm{E}-49$ \\
\hline Glyma04g17300 & -2.23 & NA & NA \\
\hline \multicolumn{4}{|l|}{ Root six hours } \\
\hline Glyma 1.1 ID & $\log _{2}$ fold change & TAIR10 annotation & E-value \\
\hline Glyma19g41920 & 5.74 & NA & NA \\
\hline Glyma13g37770 & 3.60 & Wound-responsive family protein & $3.0 \mathrm{E}-17$ \\
\hline Glyma03g39341 & 3.45 & AtPP2-B15, PP2-B15 | phloem protein 2-B15 & $1.0 \mathrm{E}-18$ \\
\hline Glyma15g10693 & 3.40 & Protein kinase superfamily protein & $2.0 \mathrm{E}-78$ \\
\hline Glyma20g00604 & 3.14 & ATOMT1, OMT1 | O-methyltransferase 1 & $6.0 \mathrm{E}-53$ \\
\hline Glyma01g06774 & 3.10 & ATBOR4, BOR4 | HCO3- transporter family & $2.0 \mathrm{E}-20$ \\
\hline Glyma05g36310 & 2.90 & ACO1, ATACO1 | ACC oxidase 1 & $2.0 \mathrm{E}-159$ \\
\hline Glyma14g39910 & 2.84 & Prolyl oligopeptidase family protein & $0.0 \mathrm{E}+00$ \\
\hline Glyma13g10791 & 2.47 & ZIP1 | zinc transporter 1 precursor & 5.0E-129 \\
\hline Glyma18g41760 & 2.36 & Proton pump interactor 1 & $2.0 \mathrm{E}-45$ \\
\hline Glyma05g09990 & -4.03 & NA & NA \\
\hline Glyma16g29233 & -3.96 & NA & NA \\
\hline Glyma16g29216 & -3.89 & Disease resistance family protein/LRR family protein & 5.0E-93 \\
\hline Glyma05g16286 & -3.86 & NA & NA \\
\hline Glyma13g12815 & -3.85 & NA & NA \\
\hline Glyma15g03080 & -3.55 & NA & NA \\
\hline Glyma04g33460 & -3.54 & NA & NA \\
\hline Glyma01g04545 & -3.53 & NA & NA \\
\hline Glyma01g04545 & -3.54 & NA & NA \\
\hline Glyma09g24780 & -3.51 & NA & NA \\
\hline
\end{tabular}

The top and bottom ten genes significantly (FDR < 0.05) differentially expressed at each time and tissue under iron stress. Glyma1.1 ID refers to Glycine max version 1.1 release. A positive $\log _{2}$ fold change represents induction in response to iron deficiency while a negative fold change represents repression in response to iron deficiency. The top A. thaliana hit (TAIR version 10) was determined by BLASTP [52] of Glyma1.1 primary proteins against $A$. thaliana proteins (TAIR10, $\mathrm{E}<10^{-6}$ ). DEGs with no BLASTP hit to A. thaliana are indicated by NA (not applicable). Full annotation information can be found in Additional files $2,3,4$ and 5 . 
response to salt, drought and ABA stress [37]. The top ten genes repressed by iron deficiency included three homo-

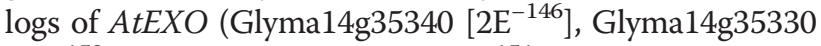
$\left[5 \mathrm{E}^{-158}\right]$ and Glyma06g10710 $\left.\left[9 \mathrm{E}^{-154}\right]\right)$. The extracellular EXO protein is essential for cell expansion and promotes shoot and root growth [38]. AtEXO mutants have altered expression of sugar-responsive genes and increased $\mathrm{ABA}$ levels. It is interesting to note that eight EXO and EXOlike (EXL5) homologs were differentially expressed in response to iron stress at this time point.

In six hour roots, 52 genes were upregulated in response to iron deficient conditions while 77 genes were downregulated. The top ten genes induced in response to iron deficiency included a homolog of a wound-responsive family

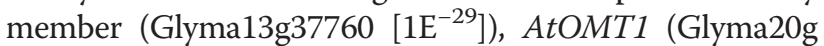

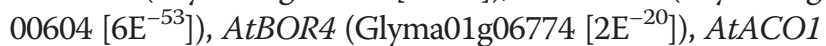

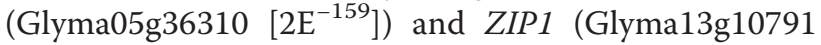
$\left.\left[5 \mathrm{E}^{-129}\right]\right)$. AtOMT1 is involved in lignin formation and the biosynthesis of sinapate esters [39]. AtBOR4 (Borate efflux transporter 4) overexpression in rice increased tolerance to excess boron [40]. Trafficking of AtBOR4 to the outer polar domain defines the root-soil interface [41]. AtACO1 (ACC oxidase 1) is an ethylene biosynthetic gene [42,43]. AtZIP1 functions as a zinc transporter, and is upregulated in AtIRT1 knockouts [44]. Interestingly, IRT1 and IRT2 are both ZIP family members. AtZIP1 appears to function in both iron and zinc homeostasis. Of the top ten genes repressed by iron stress in six hour roots, only one has an identified homolog in Arabidopsis, the function of which was unknown.

\section{DEGs located within introgressed regions associated with iron inefficiency}

Recently, introgression mapping was used to identify regions introgressed from the iron inefficient donor parent T203 to the iron efficient line Clark to develop Isoclark (iron inefficient). Collectively, Severin et al. [45] and Stec et al. [46] identified introgressed regions on soybean chromosomes 3, 4, 5, 8, 13 and 16 of Isoclark. Several studies have identified quantitative trait loci (QTL) for iron deficiency in soybean [15,47-49]. However, only the studies by Mamidi et al. [49] and Lin et al. [47,48] identified QTL on the same chromosomes as the introgressed regions. By comparing the sequences of the molecular markers used in these studies to the introgressed regions, only the QTL identified on chromosome 3 [47-49] corresponded to an introgressed region (data not shown). Five DEGs corresponded to the region on chromosome 3 [14]. In six hour leaves we identified a S-adenosyl-Lmethionine-dependent methyltransferases superfamily protein (Glyma03g28490). From one hour roots we identified a $\beta$ HLH038 homolog (Glyma03g28630), an ethylene responsive binding factor (AtERF15, Glyma03g31940) and a disease resistance-responsive protein (Glyma03g30360). Glyma03g28630 was recently identified as one of 12 candidate genes underlying the IDC QTL on soybean chromosome 3 by Peiffer et al. [14]. From six hour roots we identified a differentially expressed ethylene response factor (Glyma03g31940).

It is important to note that complex traits, such as IDC, can be the result of a number of small genes with minor effects. Therefore, it is worth noting the DEGs located within introgressed regions but not associated with a QTL. In six hour leaves, we identified a cell division control 6 ortholog (Glyma08g45230) and a sucrose-proton symporter (AtSUC2, Glyma16g27350). In roots at one hour, there were six DEGs of interest from introgressed regions including homologs of growth regulating factor 4 (AtGRF4, Glyma03g35010), expansin A7 (AtEXPA17, Glyma03g38480), Late embryogenesis abundant protein (AtNHL10, Glyma03g35920 and Glyma03g35980), flavinbinding monooxygenase protein (Glyma05g35430), and a glycosyl hydrolase (Glyma05g34850). In six hour roots, we identified a homolog of RNA-binding family protein (Glyma08g44150).

\section{Plant pathways responding to iron stress}

While these analyses identified several genes of interest, they do not highlight the major plant pathways that respond to iron deficiency. Therefore, we used the Ontologizer 2.0 software [50] to identify GO terms significantly $(\mathrm{P}<0.05)$ overrepresented within our DEGs, relative to all genes in the soybean genome (Table 2). In leaves, we identified twenty-eight significantly overrepresented gene ontology biological process (BP) terms. However, many of the DEGs were associated with multiple GO terms. Therefore, any significantly overrepresented GO terms whose genes completely overlapped were mapped to the largest significantly overrepresented GO term. In leaves, the twenty-eight original BP GO terms, were reduced to fourteen. Similarly, the 45 significantly overrepresented BP GO terms identified in roots were reduced to fifteen (Table 2). The fourteen significantly overrepresented BP GO terms identified in leaves included wax biosynthesis and metabolism (GO:0010025 and GO:0010166, P =0), defense response to bacterium (GO:0009816, P=0), and cellular response to sucrose starvation, mannitol and sorbitol (GO:0018008, GO:0018201, GO:0043617, GO:0071325, GO:0072709, $P=0.01$ ). When gene expression patterns are compared within these GO terms across time points (Figure 2), we see opposing expression patterns. For the GO terms DNA methylation and DNA unwinding involved in replication, gene expression is induced at one hour by iron deficiency, but repressed by six hours. For all other GO terms, we see the opposite expression pattern. Further, more significant expression changes, induced and repressed, are seen at the six hour time point. 
Table 2 Overrepresented GO terms in leaves and roots DEGs

Leaves description: biological processes
DNA unwinding involved in replication
Wax biosynthesis and metabolism
Defense response to bacterium
DNA methylation
Lipid metabolism
Single-organism biosynthesis and metabolism
Organic hydroxy compound biosynthesis and
Negative regulation of developmental growth
Response to stimulus
Cuticle development
Root development and morphogenesis
Cellular response to sucrose starvation, mann
Organic acid biosynthesis
Leaves description: molecular functions
Xyloglucan:xyloglucosyl transferase activity
Transferase activity, transferring acyl groups
Tetrapyrrole binding
Oxidoreductase activity
Phosphatidylinositol binding
Carboxylic ester hydrolase activity
Catalytic activity

GO terms
GO:0006268
GO:0030397
GO:0009816
GO:0006306
GO:0006629
GO:0044710, GO:0044711
GO:0006066, GO:1901615, GO:1901617
GO:0048640
GO:0050896
GO:0042335
GO:0010101, GO:0010015, GO:0010311, GO:0022411, GO:0048528
GO:0018008, GO:0018201, GO:0043617, GO:0071325, GO:0072709
GO:0016053, GO:0046394, GO:0072330

DEGs

7
$P$-value

$7 \quad 0$

GO:0016762

GO:0016746

GO:0046906

GO:0016491, GO:0016661, GO:0016701, GO:0016702

GO:0005547, GO:0043325

GO:0052689

GO:0003824

GO Terms

Roots description: biological processes

Cell junction organization and assembly

GO:0034329, GO:0034330

GO:0009913, GO:0010053, GO:0022622, GO:0048364, GO:0048640

GO:0050896, GO:0070887, GO:0071369

GO:0009698, GO:0009699, GO:0009812, GO:0009813, GO:0009962, GO:0009963, GO:0043455, GO:1900376, GO:1900378, GO:2000762

GO:0006950, GO:0006979

GO:0006829, GO:0071577

GO:0006694, GO:0008202

GO:0009804, GO:0009805

Coumarin biosynthesis and metabolism

GO:0018008

$\mathrm{N}$-terminal peptidyl-glycine $\mathrm{N}$-myristoylation

Immune system process

GO:0002376

GO:0009267

GO:0044710, GO:0044711

Single-organism biosynthesis and metabolism

GO:0044106

Cellular amine metabolic process

GO:0071554

GO:0007154

GO:0016209, GO:0016684

GO:0046906

GO:0016491

GO:0042803

0

0

0

0.005

0.007

0.007

0.009

0.01

0.012

0.041

\section{Roots description: molecular functions}

Antioxidant activity

Tetrapyrrole binding

Oxidoreductase activity 


\section{Table 2 Overrepresented GO terms in leaves and roots DEGs (Continued)}

\begin{tabular}{lll}
\hline Zinc ion transmembrane transporter activity & GO:0005385 & 6.002 \\
Regulatory region nucleic acid binding & GO:0001067 & 32 \\
ADP binding & GO:0043531 & 003 \\
Identical protein binding & GO:0042802 & 17 \\
\hline
\end{tabular}

To determine gene ontology terms overrepresented among differentially expressed genes in leaves or roots, Ontologizer 2.0 software [50] was used with parent-child-union analysis and Westfall-Young-Single-Step multiple testing correction, with a resampling of 1000 replicates. GO terms were combined when Glyma IDs overlapped entirely between two or more terms. The term containing the largest number of genes is in bold, with its corresponding P-value reported.

The fifteen significantly overrepresented BP GO terms identified in roots included response to oxidative stress and other stress (GO:0006950 and GO:0006979, $\mathrm{P}=0.002)$, zinc ion transmembrane transport (GO:0006829 and GO:0071577, $\mathrm{P}=0.003)$, response to ethylene and other stimuli (GO:0050896, GO:0070887 and GO:0071369, $\mathrm{P}=0$ ), cellular response to starvation (GO:0009267, $\mathrm{P}=$ 0.03), phenylpropanoid biosynthesis and metabolism (GO:0009698, GO:0009699, GO:0009812, GO:0009813, GO:0009962, GO:0009963, GO:0043455, GO:1900376, GO:1900378, GO:2000762, $\mathrm{P}=0.002$ ), immune system process (GO:0002376, $\mathrm{P}=0.027$ ) and steroid biosynthesis and metabolism (GO:0006694 and GO:0008202, $\mathrm{P}=0.009$ ) (Table 2). Comparing gene expression within these GO terms at one hour and six hour roots, again the most striking observation is the direction of expression changes (Figure 3). While most leaf DEGs were repressed at one hour in response to iron deficiency, most root DEGs are induced at one hour in response to deficiency. By six hours, the expression pattern has begun to reverse. It is also worth noting the overrepresented molecular function terms identified in roots included zinc ion transmembrane transporter activity (GO:0005385), suggesting metal ion transport has been activated in the root. In addition, protein homodimerization activity (GO:0042803), regulatory region nucleic acid binding (GO:0001067) and identical protein binding (GO:0042802) suggest a strong signaling component in root responses to IDC.

When we compared our lists of DEGs to known iron homeostasis genes in $A$. thaliana [51], many were found differentially expressed in both leaves and roots (Table 3 ). This serves as both a control of our hydroponic iron conditions and demonstrates how quickly soybean responds to reduced iron by increasing gene expression for iron uptake and mobilization throughout the plant. While few of these genes exhibit large fold changes $(>5)$, their function and the short response time is noteworthy. In one hour leaves, a homolog of the AtFIT1 transcription factor (Glyma09g41470, FC=-3.8) and a homolog of the phosphate transporter PHT3;1 (Glyma01g02950, $\mathrm{FC}=-2.5$ ), were repressed by iron deficiency. By six hours, there were equal numbers of genes with homology to known iron homeostasis genes in leaves that were induced or repressed by iron deficiency. The induced genes included an ortholog of the iron transporter AtNRAMP3 (Glyma17g18010, FC =4.2) and two AtBTS homologs, Glyma09g18770 and Glyma07g10400 ( $F C=3.3$ and 2.5, respectively). Only one of the four FIT1 homologs was induced (Glyma16g02320, FC=9.2), while a homolog of Yellow Stripe-like7 (YSL7) was repressed (Glyma16g33840, FC =-2.6). In roots, the response seems to initially favor an increase in transcription, and then as the iron stress persists, transport molecules such as IRT1 and VIT1 are upregulated, presumably to scavenge as much iron as possible to restore/maintain homeostasis. In one hour roots, all but one of the differentially expressed iron homeostasis genes identified were induced by iron deficiency. These included a homolog of the transcription factors AtFIT1 (Glyma01g15930, FC = 3.7), an ortholog of the transcription factor AtBHLHO38 (Glyma03g28630, $\mathrm{FC}=2.5$ ), ferric reduction oxidases AtFRO2 (Glyma16g 03770, FC $=2.8$ ) and AtFRO6 (Glyma05g00420, FC=2.8), nicotianamine synthase AtNAS2 (Glyma08g18710, FC= 2.8) and the iron transporter AtVIT1 (Glyma11g08830, $\mathrm{FC}=4.0$ ). Glyma03g28630 was recently identified as a candidate gene underlying the IDC QTL on soybean chromosome 3 [14]. In six hour roots, the homologs of the transporters AtIRT1 (Glyma06g05460, Glyma04g05410, Glyma08g17530, Glyma13g10791, Glyma15g41620 and Glyma20g06210) and an ortholog of AtNAS2 (Glyma19g 41630, $\mathrm{FC}=2.6$ ) were induced by iron deficiency, while homologs of AtVIT1 were repressed (Glyma08g08090, $\mathrm{FC}=-4.3$ and Glyma05g24980, $\mathrm{FC}=-3.2$ ).

\section{Identification of iron responsive gene families}

In order to identify gene families responding to iron stress that may not have been identified in the previous analyses, we used BLASTP $\left(\mathrm{E}<10^{-10}\right)$ [52] and single linkage clustering [53] to group all differentially expressed genes. Using this approach, we identified 161 gene families containing 2 to 38 unique sequences (Additional file 6). Eleven gene families were identified with ten or more sequences (Groups 15, 26, 29, 34, 40, 42, 46, 53, 59, 70, 81). The majority of these gene families had largely tissuespecific expression patterns and reflected the tissues in which the largest number of DEGs were identified (one hour roots and six hour leaves). Groups 26, 59, 70 and 81 


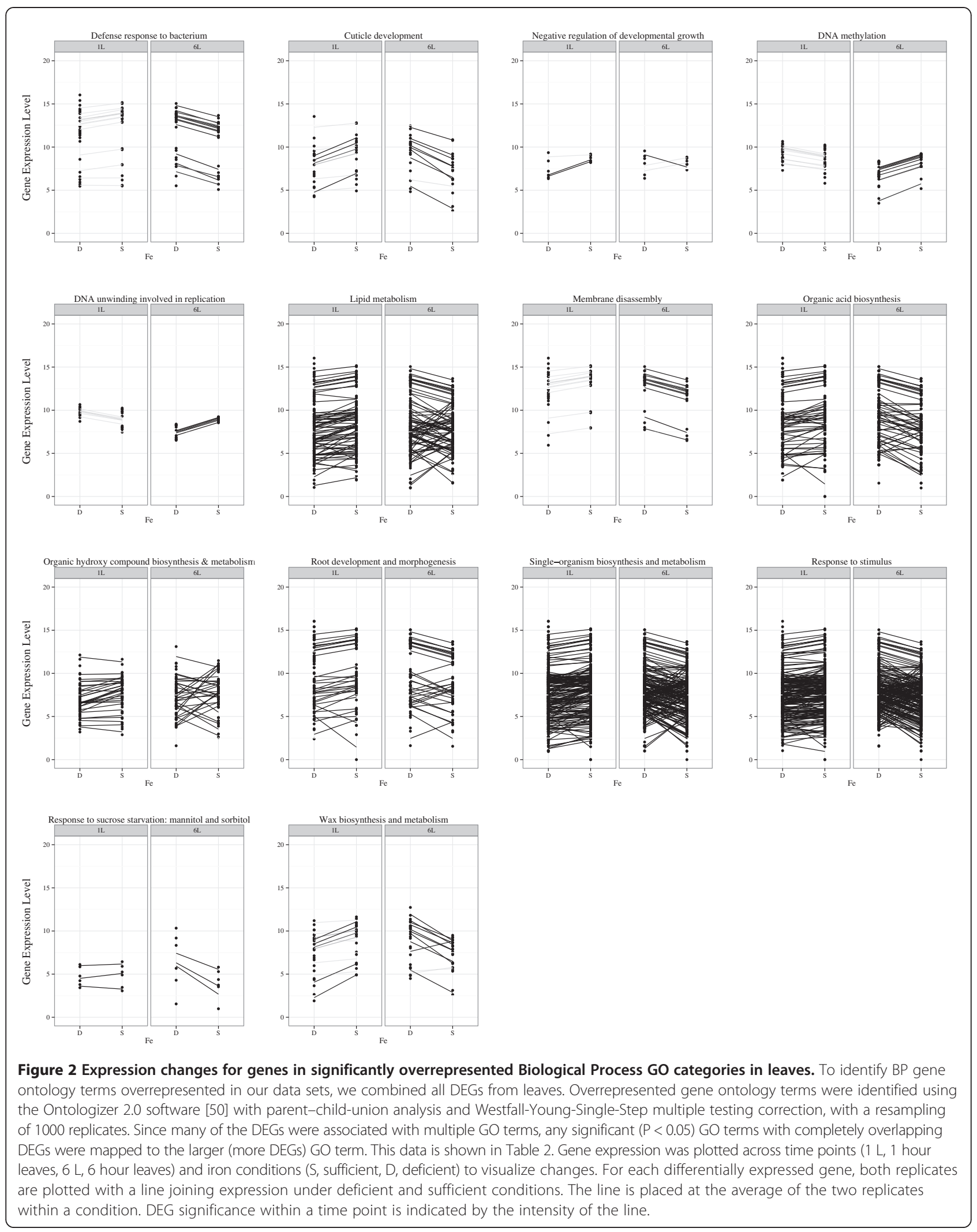




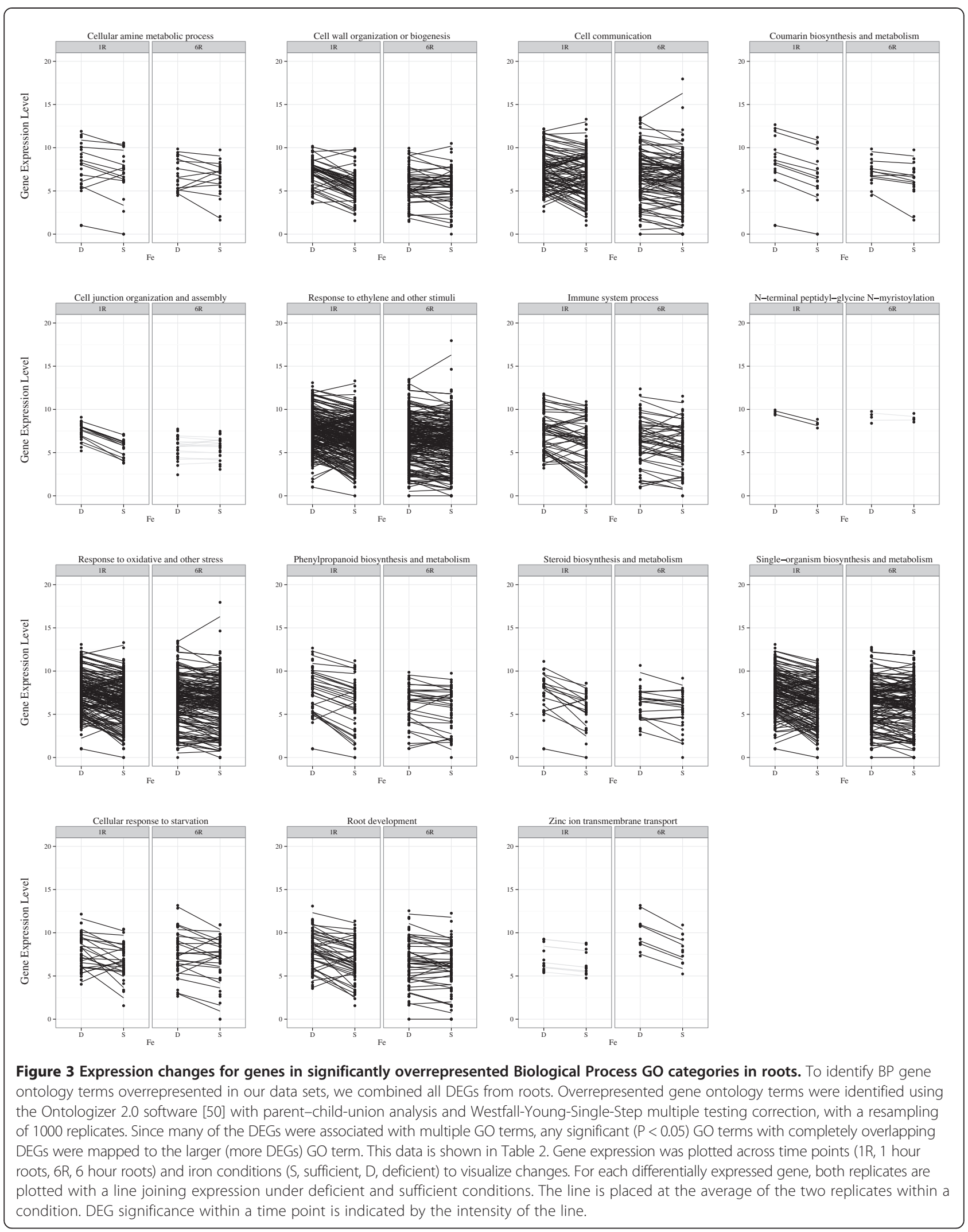


Table 3 Homologs of $A$. thaliana iron homeostasis genes found to be significantly differentially expressed

\begin{tabular}{|c|c|c|c|c|}
\hline Soybean Gene ID & Arabidopsis Gene ID & Gene function & Fold change & E-value \\
\hline \multicolumn{5}{|l|}{ One Hour Leaf } \\
\hline Glyma09g41470 & AT2G28160 & FIT1, BHLH029 & -3.84 & $1.00 \mathrm{E}-06$ \\
\hline Glyma01g02950 & AT5G14040 & PHT3;1 | phosphate transporter 3;1 & -2.53 & 8.00E-14 \\
\hline \multicolumn{5}{|l|}{ Six Hour Leaf } \\
\hline Glyma09g18770 & AT3G18290 & EMB2454, BTS | zinc finger protein-related & 3.28 & $0.0 \mathrm{E}+00$ \\
\hline Glyma07g10400 & AT3G18290 & EMB2454, BTS | zinc finger protein-related & 2.48 & $0.0 \mathrm{E}+00$ \\
\hline Glyma02g42780 & AT2G28160 & FIT1, BHLH029 & -2.48 & $1.00 \mathrm{E}-07$ \\
\hline Glyma14g05870 & AT2G28160 & FIT1, BHLH029 & -2.77 & 4.00E-07 \\
\hline Glyma01g32130 & AT2G28160 & FIT1, BHLH029 & -5.04 & $6.00 \mathrm{E}-08$ \\
\hline Glyma16g02320 & AT2G28160 & FIT1, BHLH029 & 9.24 & $7.00 \mathrm{E}-13$ \\
\hline Glyma17g12450 & AT5G14040 & PHT3;1 | phosphate transporter 3;1 & 2.20 & 8.00E-14 \\
\hline Glyma17g18010 & AT2G23150 & NRAMP3, ATNRAMP3 & 4.20 & $0.0 \mathrm{E}+00$ \\
\hline Glyma16g33840 & AT1G65730 & YSL7 | YELLOW STRIPE like 7 & -2.56 & $0.0 \mathrm{E}+00$ \\
\hline \multicolumn{5}{|l|}{ One Hour Root } \\
\hline Glyma02g14350 & AT3G60330 & AHA7, HA7| H(+) -ATPase 7 & -2.22 & 4.00E-07 \\
\hline Glyma18g38650 & AT5G62670 & AHA11, HA11 | H(+)-ATPase 11 & 4.22 & $5.0 \mathrm{E}-86$ \\
\hline Glyma05g00420 & AT5G49730 & ATFRO6, FRO6 | ferric reduction oxidase & 2.78 & $9.00 \mathrm{E}-23$ \\
\hline Glyma08g18710 & AT5G56080 ${ }^{\mathrm{a}}$ & ATNAS2, NAS2 | nicotianamine synthase 2 & 2.78 & $1.0 \mathrm{E}-89$ \\
\hline Glyma03g28630 & AT3G56970 & BHLH038, ORG2 | basic helix-loop-helix & 2.46 & $5.0 \mathrm{E}-52$ \\
\hline Glyma01g15930 & AT2G28160 & FIT1, BHLH029 & 3.68 & 5.00E-09 \\
\hline Glyma16g03770 & AT1G01580 & FRO2, FRD1, ATFRO2 | ferric reduction oxidase & 2.78 & $0.0 \mathrm{E}+00$ \\
\hline Glyma11g08830 & AT2G01770 & VIT1, ATVIT1 | vacuolar iron transporter & 3.96 & 2.00E-10 \\
\hline \multicolumn{5}{|l|}{ Six Hour Root } \\
\hline Glyma19g41630 & AT5G56080 & ATNAS2, NAS2 | nicotianamine synthase 2 & 2.64 & $3.0 \mathrm{E}-136$ \\
\hline Glyma01g02251 & AT2G28160 & FIT1, BHLH029 & 2.24 & 1.00E-15 \\
\hline Glyma06g05460 & AT4G19690 & IRT1 | iron-regulated transporter 1 & 2.99 & $2.00 \mathrm{E}-47$ \\
\hline Glyma04g05410 & AT4G19690 & IRT1 | iron-regulated transporter 1 & 2.83 & $6.00 \mathrm{E}-63$ \\
\hline Glyma08g17530 & AT4G19690 & IRT1 | iron-regulated transporter 1 & 2.72 & 7.00E-99 \\
\hline Glyma13g10791 & AT4G19690 & IRT1 | iron-regulated transporter 1 & 5.55 & 4.00E-102 \\
\hline Glyma15g41620 & AT4G19690 & IRT1 | iron-regulated transporter 1 & 2.93 & $9.00 \mathrm{E}-99$ \\
\hline Glyma20g06210 & AT4G19690 & IRT1 | iron-regulated transporter 1 & 4.10 & $2.00 \mathrm{E}-101$ \\
\hline Glyma08g08090 & AT2G01770 & VIT1, ATVIT1 | vacuolar iron transporter & -4.33 & 7.00E-11 \\
\hline Glyma05g24980 & AT2G01770 & VIT1, ATVIT1 | vacuolar iron transporter & -3.16 & $3.00 \mathrm{E}-09$ \\
\hline
\end{tabular}

Sequences of $A$. thaliana proteins identified as involved in iron homeostasis in Arabidopsis by Kobayashi and Nishizawa [51] were downloaded from The Arabidopsis Information Resource (TAIR). BLASTP $\left(E<10^{-6}\right)$ was used to compare the protein sequence of DEGs identified in this study against the known A. thaliana iron homeostasis gene protein sequences. Homologous iron homeostasis genes are shown in table, divided by time and tissue. A positive fold change indicates induction in response to iron deficiency while a negative fold change indicates repression due to iron stress. ${ }^{\mathrm{a}}$ Orthology between Arabidopsis and soybean proteins were verified by reciprocal best BLASTP.

were largely specific to six hour leaves and had homology to GDSL lipases, protein kinases, cytochrome P450s and xyloglucan endotransglucosylases, respectively. Groups 15 , $34,41,42,46$, and 53 were largely specific to one hour roots and had homology to Casparian strip membrane proteins, AP2/ERF transcription factors, peroxidases, 2oxoglutarate (2OG) and Fe(II)-dependent oxygenases, nucleotide binding site-leucine rich repeat resistance gene homologs and dirigent-like proteins, respectively.

\section{Identification of transcription factors responding to iron stress}

The reversals in gene expression found between the one and six hour time points in each tissue and the overrepresentation of GO category "regulatory region nucleic acid binding" (GO:0001067, Table 2) suggested that transcription factors play a key role in the iron deficiency stress response. Therefore, we took advantage of the SoyDB transcription factor database [54], 
http://casp.rnet.missouri.edu/soydb/) to identify transcription factors within our DEGs (Figure 4, Additional file 7). In one hour leaves, we identified two differentially expressed transcription factors, Glyma09g41470 and Glyma17g10820, both significantly repressed by iron deficiency (fold changes of -3.8 and -2.7 , respectively). After six hours of iron deficiency, only Glyma17g10820 was still significantly differentially expressed, however it was induced by iron deficiency (fold change of 3.5). Glyma09g41470 and Glyma17g10820, encode a $\beta$-helix-loop-helix and MYB/ HD-like transcription factors, respectively. Their best homologs in Arabidopsis, identified by reciprocal BLASTP [52], have no known function.

In six hour leaves, we identified 39 differentially expressed transcription factors (Figure 4). These included representatives from the AP2-EREBP (2), AUX-IAA-ARF
(1), $\beta$-helix-loop-helix (6), BZIP (6), C2C2 (Zn) CO-like (2), C2C2 (Zn) Dof (1), CCAAT (1), FHA (1), GRAS (1), Homeodomain/HOMEOBOX (7), MYB/HD-like (5), NAC (1), PLATZ (1), TPR (3) and WRKY (1) transcription factor families. Several of these have functions associated with defense or abiotic stress responses in Arabidopsis. Glyma06g05170 and Glyma08g14600 (fold changes of -4.35 and 3.48 , respectively) are homologs of the AP2-EREBP transcription factor AtDREB2C $\left(1 \mathrm{E}^{-42}\right)$ (dehydration-responsive element-binding protein) which is induced by iron deficiency. AtDREB2C interacts with the BZIP transcription factor $\mathrm{ABF} 2$ to regulate $\mathrm{ABA}$ responsive gene expression [55]. Glyma16g01940 encodes a NAC transcription factor induced in response to iron deficiency (4.2-fold). Glyma16g01940 is homologous to AtNTL9 $\left(2 \mathrm{E}^{-40}\right)$, which regulates osmotic stress signaling

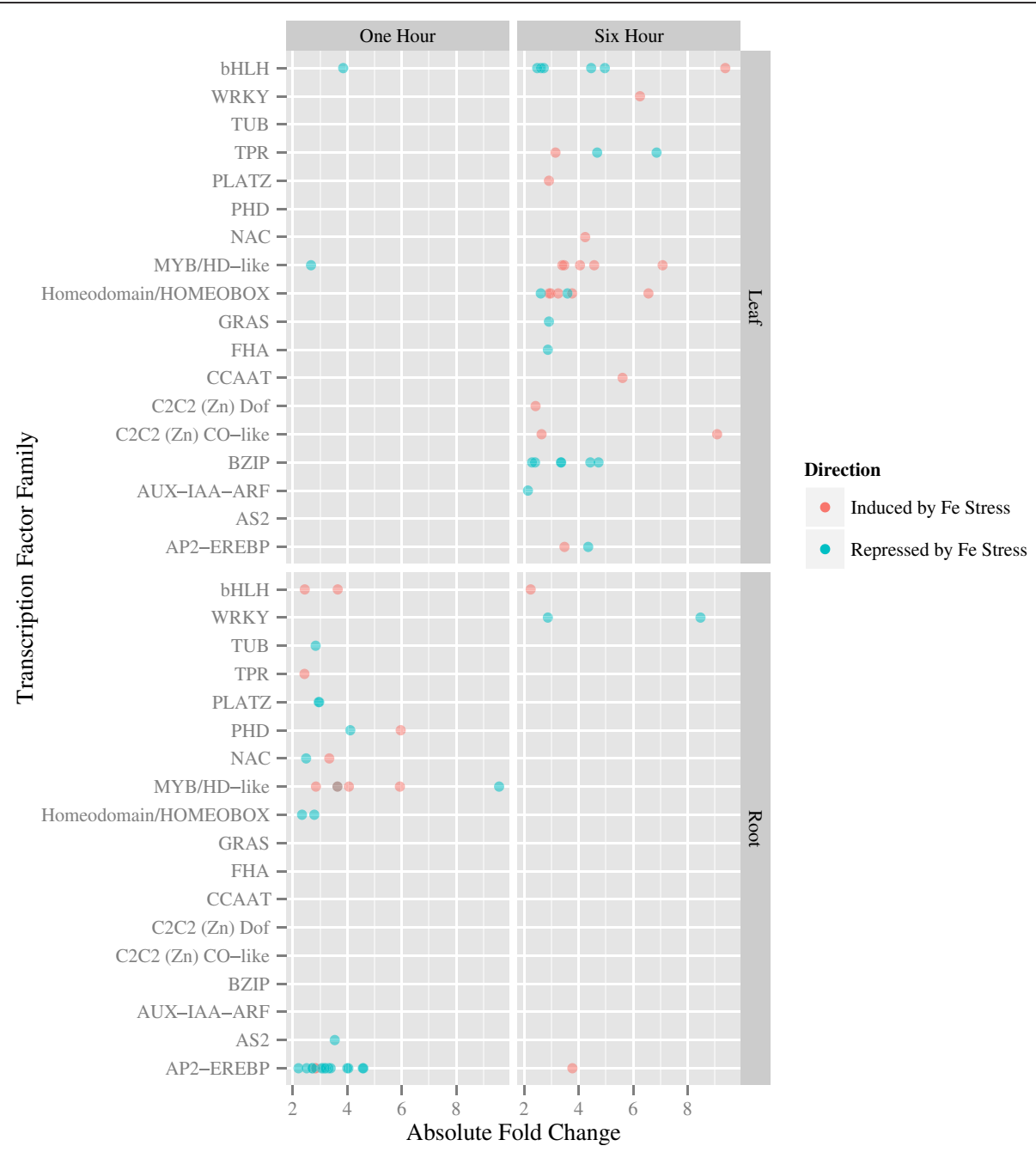

Figure 4 Expression patterns of transcription factors significantly (FDR $<0.05)$ differentially expressed between iron sufficient and deficient conditions. Transcription factor families on the $y$-axis refer to the SoyDB transcription factor database [54] as described in the methods. Absolute fold change in gene expression is plotted on the x-axis. Multiple differentially expressed transcription factors per family are plotted. Additional details on TF expression are provided in Additional file 7: Table S7. 
[56]. Glyma02g42380 encodes a MYB transcription factor related to AtMYB73, which negatively regulates SOS induction during salt stress [57].

In one hour roots, we identified 35 differentially expressed transcription factors (Figure 4). These included representative members from eight different families such as AP2-EREBP (16), AS2 (1), $\beta$-helix-loop-helix (2), Homeodomain/HOMEOBOX (2), MYB/HD-like (6), NAC (2), PHD (2), PLATZ (2), TPR (1), and TUB (1). Of the 16 AP2-EREBP proteins expressed, five are homologs of

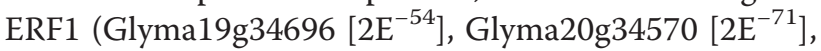

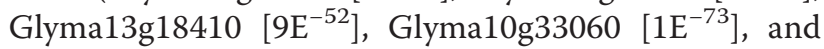
Glyma11g03910, $\left[9 \mathrm{E}^{-52}\right]$ ). ERF1 has been shown to regulate abiotic stress responses in Arabidopsis [58]. Glyma13g34920 encodes an ERF4 homolog $\left(3 \mathrm{E}^{-47}\right)$, which functions as a repressor in ethylene, jasmonic acid, and abscisic acid pathways [59]. Glyma03g28630 encodes a homolog of the $\beta$-helix-loop-helix transcription factor $\beta H L H O 38\left(5 \mathrm{E}^{-52}\right)$. This gene is upregulated under soybean iron stress conditions, and is thought to function as a binding partner for FIT [14]. Glyma16g01911 is most similar to AtNTL6 $\left(6 \mathrm{E}^{-53}\right)$, which is a plant-specific NAC that is phosphorylated by SnRK2.8 in droughtresistance [60]. The PHD family member, Glyma20g01070, is upregulated 6-fold in response to iron deficiency and is

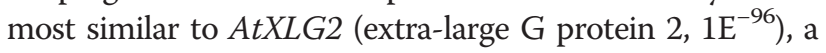
GTP-binding protein that has been implicated in resistance to Pseudomonas syringae [61].

In six hour roots, we identified four differentially expressed transcription factors. Two were upregulated in response to iron stress, Glyma03g31940 and Glyma01g02251 (fold changes of 3.8 and 2.2, respectively), and two downregulated, Glyma18g10324 and Glyma08g43258 (fold changes of -8.5 and -2.9 , respectively) (Figure 4). Only Glyma03g31940 was also significantly expressed at one hour, downregulated -3.4 fold at that time. Glyma03g31940 encodes an AP2-EREBP transcription factor $\left(8 \mathrm{E}^{-54}\right)$ homologous to AtERF15. Glyma01g02251 encodes a MYC2 homolog $(E=0)$, which is activated by the jasmonic acid signaling pathway to negatively regulate JA-mediated stress responses [62]. Glyma18g10324. and Glyma08g43258 each encode homologs of the AtWRKY6 transcription factor $\left(1 \mathrm{E}^{-88}\right.$ and $2 \mathrm{E}^{-88}$, respectively). AtWRKY6 has been implicated in senescence and defense [63], phosphate stress [64] and boron deficiency [65].

In addition to identifying individual transcription factors within each sample, we used overrepresentation analysis to identify transcription factor families significantly overrepresented among DEGs relative to their abundance in the soybean genome. Only the AP2-EREB transcription factor family was identified as significantly overrepresented $\left(\mathrm{P}<6.88 \mathrm{E}^{-05}\right)$ and only in one hour roots.

\section{Identification of transcription factor binding sites overrepresented in iron-responsive genes}

Transcriptional cascades happen quickly, and to explore pathway components outside of our one and six hour windows, we examined the transcription factor binding sites that were overrepresented in the promoters of our DEGs. We leveraged Clover (Cis element over representation) [66] and the TRANSFAC transcription factor database (version 2010, [67]) to identify transcription factor binding sites significantly $(t<0.05)$ overrepresented in promoters of DEGs relative to promoters of all predicted genes in the soybean genome.

We found 74 unique transcription factor motifs significantly overrepresented across the four tissue/time points within the DEGs. Focusing on transcription factors known to be involved in abiotic and biotic stress response, ARF, BZR1, DREB1B, HY5, MYBPH3, TGA1, and TRAB1 binding sites were all significantly overrepresented $(t<0.05)$ in promoters of genes differentially expressed in one hour leaves (Additional file 8). ARF (auxin response factor) has been implicated in both biotic and abiotic stress responses in several plant systems $[68,69]$. In our dataset, its binding site is present in a high percentage of DEG promoters (one hour leaf, 74\%; six hour leaf, 70\%; one hour root, $69.2 \%$ ). BZR1 is a central regulator of brassinosteroid (BR) signaling, synthesis and growth responses [70]. Soybean GmDREBa and $G m D R E B b$ are induced by cold, drought and salt in the leaves of seedlings. While expression of $G m D R E B C$ is low in leaves, it has high levels of expression in roots following drought, salt and ABA treatments [71]. HY5 (LONG HYPOCOTYL 5) is a bZIP transcription factor that has been shown to positively regulate anthocyanin biosynthesis [72]. The MYBPH3 transcription factor functions in the regulation of flavonoid biosynthesis in petunia [73] and may also be involved in salt and coldtolerance in pea [74]. TGA1 is controlled by nitric oxide and regulates systemic acquired resistance in plants through salicylic acid (SA)-mediated signal transduction pathway $[75,76]$. TRAB1, responsible for ABA regulation, is phosphorylated in response to osmotic stress and by the SnRK2 kinase in response to ABA [77].

In six hour leaves, ABF1, ABZ1, Alfin1, ARF, AtMYB15, AtMYB77, BZR1, C1, DREB1B, E2F, HY5, KNOX3, LIM1, MYBAS1, NAC6, OSBZ8, P, RAV1, TGA1 and TRAB1 binding sites were significantly $(t<0.05)$ overrepresented in the promoters of our DE genes and all have reported roles in stress responses (Additional file 9). ABF (ABAresponsive elements binding factor) is $\mathrm{ABA}$ and stress inducible, and in turn, activates ABREs (ABA-responsive elements) in response to abiotic stress [78]. ABZ1 (anaerobic basic leucine zipper) was isolated from a tomato cDNA library enriched for anaerobically induced genes [79]. The soybean genome contains six genes 
identified as Alfin1-type PHD finger protein and their expression responds differentially to drought, salt, cold and $A B A$ treatments when expressed transgenically in Arabidopsis [80]. Like ARF, Alfin binding sites are highly represented in our DEG promoters (six hour leaves, $74.3 \%$; one hour roots, $70.6 \%$ ). Myb factors have been implicated in a variety of biotic and abiotic stress responses [81]. Transgenic AtMYB15 can confer improved tolerance to drought and salt stress in Arabidopsis [82]. AtMYB77 expression responds to wounding, pathogen infection, abiotic stress and hormone treatment [68]. The E2F transcription factor regulates the cell cycle and DNA replication [83,84]. Atwood et al. [11] and O'Rourke et al. [13] found that DNA replication was inhibited in iron efficient soybean lines. HAHB4, a HD-Zip transcription factor, regulates crosstalk between ethylene and drought signaling in sunflower [85]. APETALA 2/ethylene-responsive element binding factor (AP2/ERF) family includes four major subfamilies: the AP2, RAV, ERF and DREB subfamilies and many have been shown to play a role in abiotic stress [86]. Binding sites for two of those subfamilies (RAV and DREB) were overrepresented in the promoters of genes from the six hour leaf time point. Knotted1-like homeobox (KNOX) genes are involved in plant morphogenesis, and barley KNOX3 has been shown to be regulated by the ethylene signaling pathway [87]. Lignin plays an important role in mechanical support, water transport and pathogen resistance. NtLIM1 encodes a Pal-box binding protein involved in lignin biosynthesis [88]. Tobacco NtMYBAS1 is involved in phenylpropanoid biosynthesis [89], which has long been known to be stress-induced [90]. Soybean GmNAC6 is induced by both endoplasmic reticulum-stress and osmotic-stress signaling to promote cell death [91]. In rice, the bZIP class Abscisic acid Responsive Element (ABRE)-binding factor, OSBZ8 has been shown to function in ABA signaling and in salt stress [92]. The P transcription factor in maize is involved in flavonoid biosynthesis, leading to the production of a red phlobaphene pigment [93,94]. AtRAV1, a RAV (Related to $A B I 3 / V \mathrm{P} 1)$ transcription factor family gene has been shown to positively regulate leaf senescence, and is induced in response to ethylene and methyl jasmonate [95]. DREB1B, TGA1, and TRAB1 binding sites were all overrepresented in both one hour and six hour leaves.

In our DE genes from one hour roots, ABZ1, Alfin1, AtMYB77, BZR1, HAHB4, MYBPH3, P, TGA1a, TGA1b, TGA2, TRAB1 and WRKY11 binding sites were overrepresented (Additional file 10). Of these 11 families, only CBNAC, TGA2 and WRKY11 binding sites are unique to one hour roots. Calmodulin-regulated transcription factors and NAC transcription factors in general have been show to function in both biotic and abiotic stresses $[96,97]$. TGA2 is involved in salicylic acid signaling in Arabidopsis [98]. WRKY11 is a negative regulator of basal defense responses in Arabidopsis [99]. Six hour DE root genes had P, RAV1, TGA1a and TGA1b binding sites overrepresented (Additional file 11). There are 14 transcription factor family binding sites overrepresented in all four time points and tissues, and 40 overrepresented in at least two time points and tissues.

\section{Discussion and conclusions}

A complicated molecular network exists to maintain iron homeostasis, as metals are necessary for many metabolic processes yet toxic to cells in high concentrations. The mechanisms for sensing deficiencies and interactions with general stress and defense pathways are poorly understood. Previous work demonstrated that iron deficiency is sensed in the leaves and that an unknown leaf signal regulates the expression of iron uptake genes in the root $[7,8]$. In order to capture signaling between the root and shoot, and to identify genes acting early in efficient responses, we sampled leaves and roots from the same plants, one and six hours after the onset of iron stress. One of our first observations was the dynamic difference between roots and shoots. At one hour of iron stress, few genes were differentially expressed in leaves but many were already changing expression in roots. By six hours, more genes were differentially expressed in the leaves, and a massive shift was seen in the direction of gene expression in both roots and shoots. Further, there was little overlap in the DEGs found in each tissue and time point.

Stein and Waters [100] and Waters et al. [101] used the Arabidopsis genome array to measure gene expression in roots and rosettes (respectively) of the same plants 24 and 48 hours after iron deficiency using two different Arabidopsis ecotypes, differing in the speed of their iron deficiency response time [100]. In the faster Kas-1 ecotype, greater differential gene expression was observed in roots (1504 DEGs) than rosettes (130 DEGs). In the slower Tsu-1 ecotype, the number of DEGs was approximately equal between roots and rosettes (630 and 690, respectively). In the faster Kas-1, $40 \%$ and $31 \%$ of DEGs were expressed in both time points in roots and rosettes, respectively. In contrast, only $16 \%$ and $10 \%$ of DEGs from Tsu- 1 roots and rosettes were common to both time points. Another interesting difference between ecotypes was that only Kas-1 root DEGs were significantly overrepresented with abiotic and biotic stress associated GO terms. In contrast, only Tsu-1 rosettes were overrepresented with abiotic and biotic stress GO terms. In our study, approximately equal numbers of DEGs were identified in roots and leaves, with very little overlap in time points, mirroring Tsu-1 responses $[100,101]$. In our experiment however, we found most GO terms associated with abiotic stress significantly overrepresented in the root, mirroring Kas-1. 
Another interesting difference is that Stein and Waters [100] found that FRO2 expression in Kas-1 significantly increased 16 hours after iron deficiency treatment, while FRO2 expression in Tsu-1 was significant only after 48 hours. In our study, we found that soybean homologs of FIT and FRO2 were induced by iron deficiency in both one and six hour roots suggesting Clark may have a faster iron efficiency response than either of the Arabidopsis ecotypes. Differences in the timing of FRO2 expression could also be due to different experimental protocols. While our study reduced available iron under hydroponic conditions, Stein and Waters [100] removed iron from the growing media completely.

To our knowledge, no other gene expression analyses have been performed on the early stages of iron deficiency examining root and shoot response simultaneously. Therefore, we expanded our comparisons to other iron deficiency experiments focused on single tissues. Buckhout et al. [102] grew Arabidopsis ecotype Landsberg erecta in Fe-sufficient hydroponic conditions, moved them into Fe-free media and collected roots 0 , $0.5,1,6$ and 24 hours later. At one hour, they identified 36 DEG (18 induced, 18 repressed). By six hours, 60 DEGs (50 induced, 10 repressed) were found. Similar to our study, very little overlap in gene expression was found between time points. However, we found greater differential gene expression in one hour roots, with 263 of 360 DEGs induced by iron deficiency. Yang et al. [103] grew two Arabidopsis accessions (Col-0 and C24) on agar media, switched to Fe-deficient agar and collected roots three days later for microarray analysis. Their goal was to identify core iron-stress response genes in Arabidopsis and categorize them into functional modules. They identified 130 and 44 genes upregulated and downregulated, respectively, in response to iron deficiency. All but one gene overlapped with the iron-stress responsive genes found in the Buckhout study [102].

We also examined studies done in response to other nutrient deficiencies. Hermans et al. [104] looked at the effect of magnesium stress on Arabidopsis roots and mature leaves 4, 8 and 28 hours after the removal of magnesium from the media. In four-hour roots, 89 of the 97 DEGs were induced by magnesium deficiency. By eight hours, 120 of 123 genes were induced and by 28 hours only 3 of 8 genes were induced by magnesium deficiency. In the leaves, 145 of 155, 104 of 106 and 286 of 410 were induced at 4,8 and 28 hours respectively by magnesium deficiency. Their time points do not allow for direct comparison with the Clark iron response, but the pattern is reminiscent in that roots show much activity early and taper off, while leaves have larger expression changes as stress persists.

One of the aims of this study was to identify genes directly involved in the uptake and utilization of iron in soybean. A recent review by Kobayashi and Nishizawa [51] generated a comprehensive list of genes known to be involved in iron homeostasis responses in higher plants. We used this data to identify homologous sequences, responding to iron deficiency, in our RNA-Seq data. The gene expression changes are similar to what has been shown in other plants. In total, we identified 29 DEGs with homology to known iron deficiency genes. In the soybean root, we see all the components of the iron transport machinery induced; AHA11, FRO2, FRO6, FIT1, IRT1, VIT1 (at one hour), and NAS2. VIT1 functions in moving iron into vacuoles for storage [105]. The repression of VIT1 at six hours of iron stress suggests that the roots are switching from storage to uptake and mobilization of stored iron as the stress persists.

In Arabidopsis, most of the genes involved in iron homeostasis have been found in both leaves and roots, with AtFIT1 notably missing from leaves [106]. It is interesting that in soybean, not only are multiple copies of FIT1 expressed in leaves, but they are differentially expressed at both one and six hours of iron stress. Yellow Stripe-like 1, 2 and 3 are well characterized in irontransport $[107,108]$, while the function of YSL7 in metal transport is only putative. We observe $Y S L 7$ responding to iron deficiency in leaves, but no other YSL homologs were significantly affected. AtBTS has been shown to function in leaf iron homeostasis [109], but more studies have been conducted on its role in the roots. Strangely, we do not see BTS in our root data, but this may be due to timing of the experiment as BTS levels are elevated in Arabidopsis roots by 24 hours of iron stress [109]. Such differences between soybean and Arabidopsis in iron response are worth investigating further.

One novel approach we used to characterize iron deficiency responses in soybean was to identify gene families among our differentially expressed genes (Additional file 6). One hour roots had a number of differentially expressed gene families with ten or more sequences. Interestingly, several of these were related to the development and maintenance of Casparian strips and all were induced by iron deficiency. Group 15 contained 13 DEGs from one hour roots orthologous to Casparian strip membrane domain proteins (CASPs) 1,3 and 5. These proteins were identified by Roppolo et al. [110] for their role in the development of Casparian strips. Group 53 contained nine DEGs from one hour roots with homology to dirigent-like proteins, including orthologs of ENHANCED SUBERIN 1 (ESB1). Recently, Hosmani et al. [111] found that ESB1 was required for the formation of Casparian strips. Group 41 contained 18 DEGs with homology to peroxidases in one hour roots. Lee et al. [112] found that peroxidase AtPER64 was also required for timely formation of Casparian strips. Other peroxidases (AtPER03, AtPER09, AtPER15, AtPER37, 
AtPER39, AtPER40, AtPER49, AtPER72) were also induced in the root endodermis relative to the rest of the root. Given these results we examined the rest of the differentially expressed genes for other genes that could function in Casparian strips. The top DEG in one hour root is a homolog of a type III peroxidase, RCI3 (Glyma10g02730), which has been shown to contribute to ROS production in potassium deficiency [29]. Four other homologs of RCI3 are also highly induced in one hour root (Glyma02g17060, Glyma03g36620, Glyma12g10850 and Glyma06g45910). An ortholog of respiratory burst oxide homolog F (AtRBOHF, Glyma05g00420) was also induced by iron stress in one hour roots. Lee et al. [112] found that RBOHF was also localized to Casparian strips and was required for their formation. Further, Lee et al. hypothesized that CASP proteins provide a scaffold for $\mathrm{RBOHF}$ to produced hydrogen peroxide which is then used by the peroxidases to polymerize lignins to form Casparian strips. The Casparian strip has been shown by Perls/DAB staining in frd3 mutants to act as a barrier to Fe within the root [113]. Additionally, we see seven homologs of NET1D (AT1G03080; Glyma17g 27187, Glyma17g23660, Glyma17g27135, Glyma13g07360, Glyma07g36351, Glyma10g14860 and Glyma15g21211) upregulated in response to iron deficiency. The NET1D family has recently been shown to be an actin-binding protein highly expressed in the stele and conducting tissues of the roots [32]. Given that Casparian strips are thought to control the passage of water and mineral nutrients into the vascular system, which would then need to pass through the stele into the xylem, it interesting to speculate that increased expression of these genes in response to iron stress could facilitate the uptake of iron.

We also identified a putative family (Group 42) of 9 2OG-Fe(II)-dependent oxygenases differentially expressed in one hour roots. While seven of these were induced by iron deficiency, two were repressed. Reciprocal best BLASTP [52] identified two orthologs of FERULOYLCOA 6' HYDROXYLASE 1 (AtF6'H1, Glyma03g23770 and Glyma07g12210), both induced by iron deficiency. Schmid et al. [114] found that F6'H1 was required for coumarin synthesis and was also induced by iron deficiency. Recently, Rodríguez-Celma et al. [115] demonstrated that Arabidopsis excretes phenolic compounds, such as coumarin, in response to low iron. Fourcroy et al. [116] found that AtPDR9 was induced by iron deficiency in Arabidopsis and was required for the secretion of coumarin compounds aiding in iron acquisition. Therefore, we examined our DEGs to identify similar genes. We found differential expression of a number of these genes in one hour roots including orthologs of pleiotrophic drug resistance protein AtPDR9 (Glyma17g03863 and Glyma07g36166), AtPDR11 (Glyma19g37760), AtPDR12 (Glyma13g43860) and caffeic acid O-methyltransferase
AtOMT1 (Glyma04g40591 and Glyma06g14210). Further, we found the GO terms associated with coumarin (GO:00098040 and phenylpropanoid (GO:0009698) biosynthesis and metabolism were significantly overrepresented in one hour roots. This suggests that secretion of coumarins is essential for iron uptake in soybean as well.

The second main aim of this study was to identify signaling genes that regulate iron deficiency responses. The virtual on/off switch of gene expression we observed between one and six hours suggests a prominent role for transcription factors in establishing and regulating early iron-stress responses in roots and leaves. Our analyses of the transcription factor families within our DEG list led to interesting results. Within the 970 DEGs in this study, there were 80 transcription factors representing 18 families. We found two transcription factors, both downregulated, in one hour leaves but 35 transcription factors representing ten families that were either induced or repressed in roots at the same time. As was true for DEGs, we saw this pattern reverse by six hours with 39 transcription factors representing 15 families differentially expressed in leaves and only four transcription factors in roots.

Transcription factor binding sites, which were overrepresented in our DEGs, correlated with this pattern as well, with six hour leaves containing the highest number of unique transcription factor binding sites, and binding sites within six hour leaf transcripts greater than six hour root transcripts. Surprisingly, the degree of overlap between transcription factor family binding sites across time points and tissues was larger than might have been expected given the differences in gene expression across time points and tissues. There were 40 transcription factor binding sites that were significantly overrepresented $(t<0.05)$ in at least two time/tissue gene lists out of 74 transcription factor binding sites significantly overrepresented in at least one time point or tissue. Many of the transcription factor families corresponding to the significant transcription factor binding sites were not identified as significantly differentially expressed themselves, suggesting that the complexity of the early stress response is greater than what we captured.

Using a combination of different approaches, we also observed evidence of hormone-related signaling in our data. Recently, Garcia et al. [117] demonstrated that genes involved in iron deficiency responses, such as AtFIT, AtBHLH38, AtFRO2, AtIRT1, AtNAS1, AtNAS2 and $A t F R D 3$, were induced in response to IDC, ethylene, and nitric oxide (NO). Our results also confirm a role for ethylene and NO in IDC responses. In one hour roots, we observed differential expression of eleven genes involved in ethylene production, all of which were induced by iron deficiency. These encode ten oxidoreductases (Glyma02g34201, Glyma04g07480, Glyma04g07490, 
Glyma07g18280, Glyma08g18011, Glyma15g33740, Glyma15g41000, Glyma16g12830, Glyma18g43136 and Glyma19g31460) and a 1-amino-cyclopropane-1-carboxylate synthase (ACC, Glyma08g03400). ACC is converted to ethylene by ACC synthase and ACC oxidase [118]. While ethylene synthesis appeared to be induced by iron deficiency in one hour roots, APETALA 2/ethylene-responsive element binding protein (AP2-EREBP) transcription factors were repressed. In six hour roots, genes involved in response to ethylene (GO:0050896, GO:0070887 and GO:0071369, $\mathrm{P}=0$ ) were significantly overrepresented and induced by iron deficiency. This included homologs of the ethylene sensors AtEIN4 (Glyma20g21780), AtEIN3 (Glyma17g31940), AtERF15 (Glyma03g31940) and AtETR2 (Glyma20g34420). Glyma03g31940 (AtERF15) has an extreme fold change of -3.4 in one hour root to 3.8 in six hour roots. The chitinase AtChiB (Glyma02g04820), PDF1.2 (Glyma03g32520) and PR4 (Glyma03g40770), which are all induced by ethylene $[119,120]$, were repressed in six hour roots. The promoters of genes differentially expressed in six hour roots had an overrepresentation of the AP2-EREBP DREB1B transcription factor binding site $\left(\mathrm{P}<1.6 \mathrm{E}^{-6}\right)$. The induction of the ethylene biosynthetic enzyme 1-aminocyclopropane-1-carboxylate oxidase (ACO1, Glyma05g36310) in six hour roots, suggests that ethylene may be required for sustained IDC signaling in soybean.

NO has protective effects on iron-stressed organisms, ranging from animals to plants [121]. Homologs of proteins involved in NO synthesis and nitrate transport such as AtNIR1 (Glyma02g14910 and Glyma07g33570), AtNRT1 (Glyma11g03430) and AtNIA1 (Glyma06g11430 and Glyma13g02510) were repressed by iron deficiency in one hour leaves, but homologs of the nitrate transporters NRT1-2 (Glyma08g407340 and Glyma08g40740) and NRT1-7 (Glyma01g04830) were induced in six hour leaves. We also found that binding sites of the NO regulated transcription factor TGA1 [75,76] were overrepresented in one hour leaves. These findings suggest NO synthesis is occurring mainly in the leaves. NO can interact with iron-sulfur cluster enzymes such as ribonuclease reductase, aconitase and NADH dehydrogenase to inhibit DNA synthesis and mobilize stored iron reserves. Aconitase ACO3 (Glyma14g12315) was induced in one hour roots while NADH dehydrogenase NAD2 (Glyma0886s50) was down in six hour roots. In Arabidopsis and cucumber, ACO1 (ACC oxidase) is involved in ethylene synthesis, has also been shown to increase NO production, and we see ACO1 (Glyma05g36310) induced in six hour roots [9]. We also see two nitrate transporters differentially expressed, but in opposite direction in roots after six hours of iron stress; AtNRT2.4 (Glyma12g08380, FC=2.95) and AtNRT1-5 (Glyma01g40850, $\mathrm{FC}=-4.38)$.
We observed other interesting signaling pathways changing in response to iron deficiency including genes involved in the sucrose efflux pathway. SWEET transport proteins act redundantly to mediate sucrose efflux in Arabidopsis [23]. atsweet11;12 double mutants were defective in phloem loading, had reduced growth, and had increased sucrose levels in the leaves. In addition, expression of SWEET proteins was tightly correlated with other sucrose synthesis and transport genes including sucrose phosphate synthase (AtSPS4F) and a sucrose transporter (AtSUC2). In our experiments we observed repression of two SWEET13 sucrose transporters (Glyma05g38340 and Glyma08g01310), a homolog of AtSPS3F (Glyma14g03300), and a homolog of AtSPS4F (Glyma15g03300) in the leaves one hour after iron stress. However, a homolog of AtSWEET12 (Glyma05g38351) was induced by iron stress in one hour leaves. By six hours after iron stress, none of the soybean SWEET genes were differentially expressed but a homolog of AtSUC2 (Glyma16g27350) was induced by iron stress. Similarly, genes involved in response to sucrose starvation were significantly overrepresented in six hour leaves (GO:0043617, $\mathrm{P}<0.05)$. Alterations in sucrose efflux could signal stressful conditions from shoot to root by limiting root growth and potentially affecting nutrient uptake.

Identifying genes involved in sugar signaling ties in with previous work from our group investigating the role of DNA replication in iron deficiency stress responses. O'Rourke et al. [13] found that genes involved in DNA replication were repressed in leaves in response to long term (14 days) iron stress in the iron efficient line Clark. Atwood et al. [11] found that DNA replication genes were differentially expressed between two near isogenic lines (Clark and Isoclark) that differed in their iron efficiency. Silencing of the DNA replication gene GmRPA3c (Replication protein A subunit 3) in Isoclark, to mimic expression in Clark, resulted in improved IDC symptoms and significantly reduced growth. RNA-Seq of silenced plants revealed GmRPA3c silencing resulted in massive transcriptional reprogramming with genes involved in defense and immunity, circadian rhythm, photosynthesis, protein modifications, growth and iron uptake and transport significantly differentially expressed. We hypothesized [11] this response was controlled by the SnRK1/TOR complex which is regulated by sucrose and heavy carbon load [122]. Activation of SnRK1, initiates a phosphorylation relay $[123,124]$ that inhibits components of the SnRK1/TOR pathway including the E2F transcription factor that controls the cell cycle and DNA replication [83]. In the analysis reported here, we see differential expression of genes involved in sucrose transport and DNA replication. In addition, we find that E2F transcription factor binding site (M01114) is significantly overrepresented $(\mathrm{P}=0)$ in six hour leaves 
and that a homolog of AtETG1 (E2F TARGET GENE 1) is repressed by iron deficiency.

In a general sense, the SnRK1/TOR signaling pathway is controlled by nutrient and energy availability inside the cell, but it remains unclear how external and endogenous signals regulate nutrient and energy status. Recently Schröder et al. [125-127] characterized the extracellularly located EXO and EXO-like (EXL) family in Arabidopsis. While EXO is required for growth under standard conditions, EXL1, EXL2 and EXL4 function to slow growth during low carbon availability. Lisso et al. [38] used exo T-DNA mutants and EXO overexpression in exo mutants coupled with sucrose and trehalose feeding studies to study the function of EXO. They found that exo mutants grew slowly, regardless of sugar levels, suggesting EXO modifies sugar responses during seedling growth. Further, EXO regulated the expression of a number of sugar responsive genes including AtDIN6 and AtSUC2. They hypothesized that EXO could link extracellular and intracellular carbon and sugar signaling. In our six hour leaf data, we identified eight homologs of EXO and EXL5 (Glyma02g37060, Glyma04g10880, Glyma06g10700, Glyma06g10710, Glyma10g32250, Glyma14g35330, Glyma14g35340 and Glyma20g35370) repressed in response to iron deficiency with fold changes ranging from -3.3 to -45.2 . Similarly, three homologs of AtDIN6 (Glyma02g39320, Glyma11g27480 and Glyma18g06840) and the homolog of AtSUC2 mentioned above were all induced by iron deficiency. These data suggest that SWEET and EXO proteins regulate the SnRK1/TOR signaling pathway in response to iron deficiency. Further, recent work by Xiong et al. [128] shows that both sucrose and glucose signaling are components of the SnRK1/TOR pathway. Our data adds support to the model proposed in Atwood et al. [11] that iron deficiency in Clark is regulated by SnRK1/TOR signaling.

The coordination of growth and developmental pathways with stress responses makes sense, however many IDC studies have focused on long term stress responses. In soybean, even short term IDC has a long lasting effect on yield [129]. While iron efficient soybean lines would seem preferable, they generally yield lower than iron inefficient lines in iron sufficient conditions [130], again suggesting a link between the regulation of growth and development and nutrient stress. Given this response, IDC tolerant soybean lines are not employed by farmers unless completely necessary. Therefore, research needs to focus on translating expression studies to the identification of target genes for crop improvement. While our analysis identified hundreds of DEGs, identifying those genes responsible for greater stress tolerance that have little or no impact on yield is an important challenge for the future.

\section{Methods}

\section{Growth conditions}

Soybean (Glycine max (L.) Merr.) line Clark (PI 548533) was germinated on germination paper for one week at the USDA-ARS green house at Iowa State University. Seedlings were transferred to hydroponics with iron sufficient media $(100 \mu \mathrm{M} \mathrm{Fe}(\mathrm{NO} 3) 3 \cdot 9 \mathrm{H} 2 \mathrm{O})$ and $3 \% \mathrm{CO} 2$ as described by Chaney et al. [131], with volumes adjusted for $10 \mathrm{~L}$ buckets. Nine days after being placed in hydroponics, the roots of all seedlings were rinsed six times in $\mathrm{diH}_{2} \mathrm{O}$ and transferred to either Fe sufficient or deficient nutrient solutions (100 $\mu \mathrm{M}$ vs. $50 \mu \mathrm{M}$ Fe(NO3)3•9H2O). Chaney et al. [131] demonstrated that these nutrient solutions distinguished iron efficient and inefficient cultivars and mimicked IDC symptoms in the field. These growth conditions have also been used in other soybean iron deficiency studies [11-15]. Whole roots and the $1^{\text {st }}$ trifoliate of plants were harvested at one hour and six hours after transfer into the separate Fe conditions and flash frozen in liquid nitrogen. Two biological replicates were harvested for each sample. As samples were collected before the onset of IDC, A15 (iron efficient) and T203 (iron inefficient) control plants were grown to verify expected IDC symptoms in Fe-deficient conditions. The tissues used in this study were the same tissues used by Atwood et al. [11] to study the effect of iron deficiency on DNA replication genes.

\section{RNA isolation}

Flash frozen tissue was ground in liquid nitrogen with a mortar and pestle. RNA was extracted using a Qiagen ${ }^{\circledR}$ RNeasy ${ }^{\circledR}$ Plant Mini Kit (Qiagen ${ }^{\circledR}$, Germantown, MD). The manufacturer's protocol was followed using $~ 300$ $\mathrm{mg}$ of ground tissue which was lysed using the RLT buffer and tubes were incubated at $56^{\circ} \mathrm{C}$ for two minutes with $800 \mathrm{rpm}$ shaking to aid in tissue disruption. RNA was treated with an Ambion ${ }^{\circledR}$ TURBO DNA-free ${ }^{\text {Tw }}$ kit $^{(1)}$ (Ambion ${ }^{\circledR}$, Austin, TX) to remove all contaminating DNA. RNA quality was analyzed using an Agilent ${ }^{\circledR}$ 2100 Bioanalyzer TM (Agilent ${ }^{\circledR}$, Santa Clara, CA). RNA was considered to be of good quality if the RNA was not degraded or was only marginally degraded. Equal amounts of RNA from three plants were pooled for each biological replicate prior to sequencing. In addition, the same RNA samples were used by Atwood et al. [11] to measure differential gene expression of Replication Protein A subunits by quantitative reverse transcription polymerase chain reaction.

\section{RNA-Seq and data analysis}

Sequencing was performed at the National Center for Genome Resources on an Illumina Genome Analyzer II as described by Peiffer et al. [14]. In brief, 16 multiplex libraries were prepared from two biological replicates of 
the eight samples (one and six hour samples of roots grown in sufficient or deficient Fe conditions and leaves grown in sufficient or deficient Fe conditions). Libraries were sequenced for 36 cycles to produce a total of $507,784,149$ single-end reads. TopHat (version 2.0.3, [132]) was used to align paired reads to the Williams 82 reference genome sequence using default settings (version G. max 1.1, [16]). The program samtools [133] was used to remove unreliably mapped reads. The resulting mapping files (bam) were imported into the statistical program R (R Development Core Team 2006) using the Bioconductor package Rsamtools [134]. The Bioconductor package rtracklayer [135] was used to import the gene feature file corresponding to G. $\max$ version 1.1 [16]. The package GenomicRanges [136] was used to count reads and output a matrix containing gene counts for each sample. Genes with counts per million $(\mathrm{cpm})<$ 1 in at least two of the four samples being compared were eliminated from the analyses. Count tables for all genes are provided in Additional files 12, 13, 14 and 15. The Bioconductor package edgeR [17,137-139] was used for single factor, pairwise comparisons to calculate normalization factors, estimate tagwise dispersion and determine differential expression (DE). Differential expression compared iron sufficient conditions to the iron deficient conditions (D/S). The R graphics program ggplot2 [18] was used to compare sample replicates for technical reproducibility (data not shown) and to create porcupine plots comparing gene expression of DEGs and their replicates to all other expressed genes. Data was visualized at multiple FDR (Figure 1, Additional file 1). Following visual assessment, DE genes were considered significant if their fold change was greater than two with a false discovery rate $($ FDR $)<0.05$.

\section{Annotation of DEGs}

DEGs were annotated using the SoyBase Genome Annotation Report page (http://soybase.org/genomeannotation/ index.php). In brief, primary proteins of G. max version 1.1 were compared to the UniRef100 protein database (version 11/26/2012, [20] and all predicted proteins from the $A$. thaliana genome (The Arabidopsis Information Resource version 10) using BLASTP $\left(\mathrm{E}<10^{-6}\right.$, BLAST version 2.2.27, [52]. BLAST reports from Uniref100 were parsed using custom Perl scripts to identify the top BLASTP hit and the most informative BLASTP hit. Informative BLASTP hits were identified by removing hits containing the key words predicted, hypothetical, related, and scaffold. Custom Perl scripts were used to assign gene ontology (GO) biological process and molecular function terms [140] information from the top A. thaliana hit to the corresponding soybean protein. To identify gene ontology terms overrepresented among DEGs from each tissue, we used Ontologizer 2.0 software [50] with parent- child-union analysis and Westfall-Young-Single-Step multiple testing correction, with a resampling of 1000 replicates [141]. DEGs from each time point within a tissue were combined. The gene ontology information from Arabidopsis (described above) was used to create a gene associate file for soybean for use with Ontologizer.

In order to identify transcription factors present within the DE genes, we took advantage of the SoyDB transcription factor database [54]. However, the database had not been updated to reflect changes in G. max version 1.1 [16]. Best reciprocal BLASTP $\left([52], \mathrm{E}<10^{-6}\right)$ was used to compare all predicted proteins in G. $\max 1.0$ to all predicted proteins from G. $\max 1.1$. Custom Perl scripts were then used to assign transcription factors in SoyDB to a G. max 1.1 identifier. Of the 5,683 transcription factors present in SoyDB, 5,124 (90\%) were assigned G. max 1.1 identifiers. To identify overrepresented transcription factor families, a Fisher's exact text [142] was used with a Bonferroni correction [143] $(\mathrm{P}<0.05)$ to compare the number of times each transcription factor family was found within the DEGs relative to representation in the soybean genome.

To identify soybean orthologs of known iron homeostasis genes in Arabidopsis, we leveraged the work of Kobayashi and Nishizawa [51], which identified genes involved in iron regulation, uptake and/or translocation. To identify orthologous sequences, the corresponding protein sequences were used for best reciprocal BLASTP $\left([52], \mathrm{E}<10^{-6}\right)$ against all predicted primary proteins in G. $\max 1.1$ [16]. The Arabidopsis proteins were involved in iron regulation, uptake and/or translocation. To account for whole genome duplication events in soybeans' evolutionary history, each Arabidopsis protein was allowed to hit two soybean proteins. Soybean proteins were considered putative orthologs if they identified the original Arabidopsis query sequence.

\section{Identification of differentially expressed gene families}

Single linkage clustering (as described by [53]) was used identify gene families that could be acting in iron deficiency responses. In short, protein sequences corresponding to all differentially expressed genes were compared against themselves using BLASTP ([52], $\mathrm{E}<10^{-10}$ ). Proteins with overlapping BLAST reports were assigned to groups representing potential gene families. For genes of interest, orthology to genes in Arabidopsis was confirmed using best reciprocal BLASTP ([52], E $<10^{-10}$ ).

\section{Transcription factor binding site analysis}

Clover (Cis element over representation), [66] was used in conjunction with the TRANSFAC transcription factor database (version 2010, [67]) to identify transcription factor binding sites that were significantly $(t<0.05)$ overrepresented in promoters of DEGs when compared to 
the promoters of all predicted genes in the soybean genome. Custom Perl scripts were used to mine the soybean gene features file [16] (www.phytozome.net) and identify 1000 bases of promoter sequence for each predicted gene. Promoters were defined as the 1000 base pairs upstream of the start ATG. Promoters less than 1000 bases or containing two or more ambiguous bases $(\mathrm{N})$ were removed from the analyses. Clover [66] was run using a $t$-value cutoff of $t<0.05$. The promoters of all predicted proteins in the soybean genome were used to correct for oversampling.

\section{Additional files}

Additional file 1: Genes significantly differentially expressed in response to iron stress at FDR $<0.01$. Significantly differentially expressed genes $(D E G s)(F D R<0.01)$ were identified by comparing gene expression in iron deficient conditions to iron sufficient conditions (D/S). Porcupine plots were used to visualize the expression of all genes and all DEGs. Expression of all genes is shown in grey. Expression of DEGs is shown in red (repressed by iron deficiency) and blue (induced by iron deficiency). A line joins replicates of DEGs. A. DEGs from leaves after one hour of iron stress. B. DEGs from leaves after six hours of iron stress. C. DEGs from roots after one hour of iron stress. D. DEGs from roots after six hours of iron stress.

Additional file 2: Genes significantly differentially expressed in leaves one hour post iron stress. Glyma1.1 ID refers to Glycine max version 1.1 release. For more information see http://www.phytozome.net/ soybean.php. The top descriptive Uniref100 BLASTP hit was determined via BLASTP [52] of Glyma1.1 primary proteins against Uniref100 (version 11/26/2012). The generated BLAST report was parsed to eliminate uninformative hits with descriptions including the words uncharacterized, putative, related, predicted, orf or expressed. Descriptions containing Arabidopsis or Rice gene identifiers (AtXgXXXXX, OsXXgXXXXXX) were also ignored. A minimum $\mathrm{E}$-value score $\mathrm{E}<10^{-6}$ was required. The percent coverage determined by dividing the top high scoring pair length by predicted protein length. The top A. thaliana hit (TAIR version 10) was determined by BLASTP of Glyma1.1 primary proteins against $A$. thaliana proteins $\left(\mathrm{TAIR} 10, \mathrm{E}<10^{-6}\right)$. Gene ontology information was inferred from the top A. thaliana protein.

Additional file 3: Genes significantly differentially expressed in leaves six hours post iron stress. Glyma1.1 ID refers to Glycine max version 1.1 release. For more information see http://www.phytozome.net/ soybean.php. The top descriptive Uniref100 BLASTP hit was determined via BLASTP [52] of Glyma1.1 primary proteins against Uniref100 (version 11/26/2012). The generated BLAST report was parsed to eliminate uninformative hits with descriptions including the words uncharacterized, putative, related, predicted, orf or expressed. Descriptions containing Arabidopsis or Rice gene identifiers (AtXgXXXXX, OsXXgXXXXX) were also ignored. A minimum $\mathrm{E}$-value score $\mathrm{E}<10-6$ was required. The percent coverage determined by dividing the top high scoring pair length by predicted protein length. The top $A$. thaliana hit (TAIR version 10) was determined by BLASTP of Glyma1.1 primary proteins against $A$. thaliana proteins $\left(T A I R 10, E<10^{-6}\right.$ ). Gene ontology information was inferred from the top A. thaliana protein.

Additional file 4: Genes significantly differentially expressed in roots one hour post iron stress. Glyma1.1 ID refers to Glycine max version 1.1 release. For more information see http://www.phytozome.net/ soybean.php. The top descriptive Uniref100 BLASTP hit was determined via BLASTP [52] of Glyma1.1 primary proteins against Uniref100 (version 11/26/2012). The generated BLAST report was parsed to eliminate uninformative hits with descriptions including the words uncharacterized, putative, related, predicted, orf or expressed. Descriptions containing Arabidopsis or Rice gene identifiers (AtXgXXXXX, OsXXXgXXXXX) were also ignored. A minimum $\mathrm{E}$-value score $\mathrm{E}<10^{-6}$ was required. The percent coverage determined by dividing the top high scoring pair length by predicted protein length. The top A. thaliana hit (TAIR version 10) was determined by BLASTP of Glyma1.1 primary proteins against $A$. thaliana proteins (TAIR10, $\mathrm{E}<10^{-6}$ ). Gene ontology information was inferred from the top A. thaliana protein.

Additional file 5: Genes significantly differentially expressed in roots six hours post iron stress. Glyma1.1 ID refers to Glycine max version 1.1 release. For more information see http://www.phytozome.net/ soybean.php. The top descriptive Uniref100 BLASTP hit was determined via BLASTP [52] of Glyma1.1 primary proteins against Uniref100 (version 11/26/2012). The generated BLAST report was parsed to eliminate uninformative hits with descriptions including the words uncharacterized, putative, related, predicted, orf or expressed. Descriptions containing Arabidopsis or Rice gene identifiers (AtXgXXXXX, OsXXgXXXXX) were also ignored. A minimum $\mathrm{E}$-value score $\mathrm{E}<10^{-6}$ was required. The percent coverage determined by dividing the top high scoring pair length by predicted protein length. The top $A$. thaliana hit (TAIR version 10) was determined by BLASTP of Glyma1.1 primary proteins against $A$. thaliana proteins $\left(T A I R 10, E<10^{-6}\right)$. Gene ontology information was inferred from the top A. thaliana protein.

Additional file 6: Gene families identified among DEGs. Protein sequences corresponding to all differentially expressed genes were compared to each other using BLASTP $\left([52], E<10^{-10}\right)$. Single linkage clustering [53] was used to identify groups of proteins with overlapping BLAST reports representing potential gene families.

Additional file 7: Significantly differentially expressed transcription factors.

Additional file 8: Significantly overrepresented transcription factor binding sites within one hour leaves DEGs.

Additional file 9: Significantly overrepresented transcription factor binding sites within six hour leaves DEGs.

Additional file 10: Significantly overrepresented transcription factor binding sites within one hour roots DEGs.

Additional file 11: Significantly overrepresented transcription factor binding sites within six hour roots DEGs.

Additional file 12: Normalized gene count table for one hour leaf samples. The following abbreviations are used: C Clark, L leaf, D deficient Fe condition, S sufficient Fe condition, A Sample A and B Sample B.

Additional file 13: Normalized gene count table for six hour leaf samples. The following abbreviations are used: C Clark, L leaf, D deficient Fe condition, S sufficient Fe condition, A Sample A and B Sample B.

Additional file 14: Normalized gene count table for one hour root samples. The following abbreviations are used: C Clark, R root, D deficient Fe condition, S sufficient Fe condition, A Sample A and B Sample B.

Additional file 15: Normalized gene count table for six hour root samples. The following abbreviations are used: C Clark, R root, D deficient Fe condition, S sufficient Fe condition, A Sample A and B Sample B.

\section{Competing interests}

The authors declare that they have no competing interests.

\section{Authors' contributions}

ANML performed the data analysis and drafted the manuscript. GAP generated the plant material, extracted RNA and submitted it for RNA-Seq. TY and DC assisted in bioinformatic and statistical analysis of the data. SAW participated in design of the study and helped draft the manuscript. RCS conceived of the study and participated in its design and coordination. MAG conceived of the study, participated in its design and coordination, performed data analysis and helped to draft the manuscript. All authors read and approved the final manuscript.

\section{Acknowledgements}

We thank Dr. Jamie O'Rourke and Lori Lincoln for review of the manuscript. This work is supported by the North Central Soybean Research Program, the lowa Soybean Association and USDA-ARS CRIS Project 3625-21220-005-00D. 


\section{Author details}

${ }^{1}$ USDA-Agricultural Research Service, Corn Insects and Crop Genetics Research Unit, 1565 Agronomy Hall, Ames, IA 50011, USA. ²Department of Statistics, lowa State University, Ames, lowa 50011, USA. ${ }^{3}$ Department of Plant Pathology and Microbiology, lowa State University, Ames, lowa 50011 USA. ${ }^{4}$ Department of Agronomy, lowa State University, Ames, lowa 50011, USA

Received: 14 May 2014 Accepted: 12 August 2014

Published: 22 August 2014

\section{References}

1. Hansen NC, Jolley VD, Naeve SL, Goos RJ: Iron deficiency of soybean in the north central US and associated soil properties. Soil Sci Plant Nutr 2004, 50(7):983-987.

2. Aust SD, Morehouse LA, Thomas CE: Role of metals in oxygen radical reactions. J Free Radic Biol Med 1985, 1(1):3-25.

3. Marschner H: Mineral Nutrition of Higher Plants. 2nd edition. London; San Diego: Academic Press; 1995

4. Robinson NJ, Procter CM, Connolly EL, Guerinot ML: A ferric-chelate reductase for iron uptake from soils. Nature 1999, 397(6721):694-697.

5. Colangelo EP, Guerinot ML: The essential basic helix-loop-helix protein FIT1 is required for the iron deficiency response. Plant Cell 2004, 16(12):3400-3412.

6. Vert G, Grotz N, Dedaldechamp F, Gaymard F, Guerinot ML, Briat JF, Curie C: IRT1, an Arabidopsis transporter essential for iron uptake from the soil and for plant growth. Plant Cell 2002, 14(6):1223-1233.

7. Vert GA, Briat JF, Curie C: Dual regulation of the Arabidopsis high-affinity root iron uptake system by local and long-distance signals. Plant Physiol 2003, 132(2):796-804

8. Enomoto Y, Goto F: Long-distance signaling of iron deficiency in plants. Plant Signal Behav 2008, 3(6):396-397.

9. Garcia MJ, Suarez V, Romera FJ, Alcantara E, Perez-Vicente R: A new model involving ethylene, nitric oxide and Fe to explain the regulation of Fe-acquisition genes in Strategy I plants. Plant Physiol Biochem 2011, 49(5):537-544

10. Bernard RL: Genetic stocks available. Soybean Genetic Newsletter 1975 2:57-74

11. Atwood SE, O'Rourke JA, Peiffer GA, Yin T, Majumder M, Zhang C, Cianzio SR, Hill JH, Cook D, Whitham SA, Shoemaker RC, Graham MA: Replication protein $A$ subunit 3 and the iron efficiency response in soybean. Plant Cell Environ 2014, 37(1):213-234.

12. O'Rourke JA, Charlson DV, Gonzalez DO, Vodkin LO, Graham MA, Cianzio SR, Grusak MA, Shoemaker RC: Microarray analysis of iron deficiency chlorosis in near-isogenic soybean lines. BMC Genomics 2007, 8:476.

13. O'Rourke JA, Nelson RT, Grant D, Schmutz J, Grimwood J, Cannon S, Vance CP, Graham MA, Shoemaker RC: Integrating microarray analysis and the soybean genome to understand the soybeans iron deficiency response. BMC Genomics 2009, 10:376.

14. Peiffer GA, King KE, Severin AJ, May GD, Cianzio SR, Lin SF, Lauter NC, Shoemaker RC: Identification of candidate genes underlying an iron efficiency quantitative trait locus in soybean. Plant Physiol 2012, 158(4):1745-1754

15. Wang J, McClean PE, Lee R, Goos RJ, Helms T: Association mapping of iron deficiency chlorosis loci in soybean (Glycine max L. Merr.) advanced breeding lines. Theor App/ Genet 2008, 116(6):777-787.

16. Schmutz J, Cannon SB, Schlueter J, Ma J, Mitros T, Nelson W, Hyten DL, Song Q, Thelen JJ, Cheng J, Xu D, Hellsten U, May GD, Yu Y, Sakurai T, Umezawa T, Bhattacharyya MK, Sandhu D, Valliyodan B, Lindquist E, Peto M, Grant D, Shu S, Goodstein D, Barry K, Futrell-Griggs M, Abernathy B, Du J, Tian Z, Zhu L, et al: Genome sequence of the palaeopolyploid soybean. Nature 2010, 463(7278):178-183.

17. Robinson MD, McCarthy DJ, Smyth GK: edgeR: a Bioconductor package for differential expression analysis of digital gene expression data. Bioinformatics 2010, 26(1):139-140

18. Wickham H: Ggplot2: Elegant Graphics for Data Analysis. In Use R!. New York: Series Springer; 2009.

19. Cook D, Hofmann H, Lee E, Yan H, Nikolau B, Wurtele E: Exploring gene expression data, using plots. J Data Sci 2007, 5:151-182.

20. Apweiler R, Bairoch A, Wu CH, Barker WC, Boeckmann B, Ferro S, Gasteige E, Huang H, Lopez R, Magrane M, Martin MJ, Natale DA, O'Donovan C,
Redaschi N, Yeh LS: UniProt: the Universal Protein knowledge base. Nucleic Acids Res 2004, 32(Database issue):D115-119.

21. Rietz S, Dermendjiev G, Oppermann E, Tafesse FG, Effendi Y, Holk A, Parker JE, Teige M, Scherer GF: Roles of Arabidopsis patatin-related phospholipases a in root development are related to auxin responses and phosphate deficiency. Mol Plant 2010, 3(3):524-538.

22. Herzog M, Dorne AM, Grellet F: GASA, a gibberellin-regulated gene family from Arabidopsis thaliana related to the tomato GAST1 gene. Plant Mol Biol 1995, 27(4):743-752

23. Chen LQ, Qu XQ, Hou BH, Sosso D, Osorio S, Fernie AR, Frommer WB: Sucrose efflux mediated by SWEET proteins as a key step for phloem transport. Science 2012, 335(6065):207-211.

24. Rea G, Metoui O, Infantino A, Federico R, Angelini R: Copper amine oxidase expression in defense responses to wounding and Ascochyta rabiei invasion. Plant Physiol 2002, 128(3):865-875.

25. Moller SG, Urwin PE, Atkinson HJ, McPherson MJ: Nematode-induced expression of atao1, a gene encoding an extracellular diamine oxidase associated with developing vascular tissue. Physiol Mol Plant Phatol 1998 53(2):73-79

26. Zhao $M G$, Chen $L$, Zhang $L L$, Zhang $W H$ : Nitric reductase-dependent nitric oxide production is involved in cold acclimation and freezing tolerance in Arabidopsis. Plant Physiol 2009, 151(2):755-767.

27. Shapiro AD: Nitric oxide signaling in plants. Vitam Horm 2005, 72:339-398.

28. Carretero-Paulet L, Ahumada I, Cunillera N, Rodriguez-Concepcion M, Ferrer A, Boronat A, Campos N: Expression and molecular analysis of the Arabidopsis DXR gene encoding 1-deoxy-D-xylulose 5-phosphate reductoisomerase, the first committed enzyme of the 2-C-methyl-D-erythritol 4-phosphate pathway. Plant Physiol 2002, 129(4):1581-1591.

29. Kim MJ, Ciani S, Schachtman DP: A peroxidase contributes to ROS production during Arabidopsis root response to potassium deficiency. Mol Plant 2010, 3(2):420-427.

30. Llorente F, Lopez-Cobollo RM, Catala R, Martinez-Zapater JM, Salinas J: A novel cold-inducible gene from Arabidopsis, $\mathrm{RCl} 3$, encodes a peroxidase that constitutes a component for stress tolerance. Plant J 2002, 32(1):13-24

31. Borges A, Tsai SM, Caldas DG: Validation of reference genes for RT-qPCR normalization in common bean during biotic and abiotic stresses. Plant Cell Rep 2012, 31(5):827-838.

32. Hawkins TJ, Deeks MJ, Wang P, Hussey PJ: The evolution of the actin binding NET superfamily. Front Plant Sci 2014, 5:254

33. Zhang Z, Barlow JN, Baldwin JE, Schofield CJ: Metal-catalyzed oxidation and mutagenesis studies on the iron(II) binding site of 1-aminocyclopropane-1-carboxylate oxidase. Biochemistry 1997, 36(50):15999-16007.

34. Singh K, Singla-Pareek SL, Pareek A: Dissecting out the crosstalk between salinity and hormones in roots of Arabidopsis. OMICS 2011, 15(12):913-924.

35. Yamaguchi-Shinozaki K, Shinozaki K: The plant hormone abscisic acid mediates the drought-induced expression but not the seed-specific expression of $r d 22$, a gene responsive to dehydration stress in Arabidopsis thaliana. Mol Gen Genet 1993, 238(1-2):17-25.

36. Kumar K, Rao KP, Biswas DK, Sinha AK: Rice WNK1 is regulated by abiotic stress and involved in internal circadian rhythm. Plant Signal Behav 2011, 6(3):316-320.

37. Wang H, Liu D, Sun J, Zhang A: Asparagine synthetase gene TaASN1 from wheat is up-regulated by salt stress, osmotic stress and ABA. J Plant Physiol 2005, 162(1):81-89.

38. Lisso J, Schroder F, Mussig C: EXO modifies sucrose and trehalose responses and connects the extracellular carbon status to growth. Front Plant Sci 2013, 4:219.

39. Goujon T, Sibout R, Pollet B, Maba B, Nussaume L, Bechtold N, Lu F, Ralph J, Mila I, Barriere $Y$, Lapierre C, Jouanin L: A new Arabidopsis thaliana mutant deficient in the expression of O-methyltransferase impacts lignins and sinapoyl esters. Plant Mol Biol 2003, 51(6):973-989.

40. Kajikawa M, Fujibe T, Uraguchi S, Miwa K, Fujiwara T: Expression of the Arabidopsis borate efflux transporter gene, AtBOR4, in rice affects the xylem loading of boron and tolerance to excess boron. Biosci Biotechnol Biochem 2011, 75(12):2421-2423.

41. Langowski L, Ruzicka K, Naramoto S, Kleine-Vehn J, Friml J: Trafficking to the outer polar domain defines the root-soil interface. Curr Biol 2010, 20(10):904-908. 
42. Cooper W, Bouzayen M, Hamilton A, Barry C, Rossall S, Grierson D: Use of transgenic plants to study the role of ethylene and polygalacturonase during infection of tomato fruit by Colletotrichum gloeosporioides. Plant Pathol 1998, 47(3):308-316.

43. Hamilton AJ, Lycett GW, Grierson D: Antisense gene that inhibits synthesis of the hormone ethylene in transgenic plants. Nature 1990, 346(6281):284-287.

44. Henriques R, Jasik J, Klein M, Martinoia E, Feller U, Schell J, Pais MS, Koncz C: Knock-out of Arabidopsis metal transporter gene IRT1 results in iron deficiency accompanied by cell differentiation defects. Plant Mol Biol 2002, 50(4-5):587-597.

45. Severin AJ, Peiffer GA, Xu WW, Hyten DL, Bucciarelli B, O'Rourke JA, Bolon YT, Grant D, Farmer AD, May GD, Vance CP, Shoemaker RC, Stupar RM: An integrative approach to genomic introgression mapping. Plant Physiol 2010, 154(1):3-12.

46. Stec AO, Bhaskar PB, Bolon YT, Nolan R, Shoemaker RC, Vance CP, Stupar $\mathrm{RM}$ : Genomic heterogeneity and structural variation in soybean near isogenic lines. Front Plant Sci 2013, 4:104.

47. Lin S, Cianzio S, Shoemaker R: Mapping genetic loci for iron deficiency chlorosis in soybean. Mol Breed 1997, 3(3):219-229.

48. Lin SF, Grant D, Cianzio S, Shoemaker R: Molecular characterization of iron deficiency chlorosis in soybean. J Plant Nutr 2000, 23(11-12):1929-1939.

49. Mamidi S, Chikara S, Goos RJ, Hyten DL, Annam D, Moghaddam SM, Lee RK, Cregan PB, McClean PE: Genome-wide association analysis identifies candidate genes associated with iron deficiency chlorosis in soybean Plant Genome-Us 2011, 4(3):154-164.

50. Bauer S, Grossmann S, Vingron M, Robinson PN: Ontologizer 2.0-a multifunctional tool for $\mathrm{GO}$ term enrichment analysis and data exploration. Bioinformatics 2008, 24(14):1650-1651.

51. Kobayashi T, Nishizawa NK: Iron uptake, translocation, and regulation in higher plants. Annu Rev Plant Biol 2012, 63:131-152.

52. Altschul SF, Madden TL, Schaffer AA, Zhang J, Zhang Z, Miller W, Lipman DJ: Gapped BLAST and PSI-BLAST: a new generation of protein database search programs. Nucleic Acids Res 1997, 25(17):3389-3402

53. Graham MA, Ramirez M, Valdes-Lopez O, Lara M, Tesfaye M, Vance CP, Hernandez G: Identification of candidate phosphorus stress induced genes in Phaseolus vulgaris through clustering analysis across several plant species. Funct Plant Biol 2006, 33(8):789-797.

54. Wang Z, Libault M, Joshi T, Valliyodan B, Nguyen HT, Xu D, Stacey G, Cheng J: SoyDB: a knowledge database of soybean transcription factors. BMC Plant Biol 2010, 10:14.

55. Lee SJ, Kang JY, Park HJ, Kim MD, Bae MS, Choi HI, Kim SY: DREB2C interacts with $A B F 2$, a bZIP protein regulating abscisic acid-responsive gene expression, and its overexpression affects abscisic acid sensitivity. Plant Physiol 2010, 153(2):716-727

56. Yoon HK, Kim SG, Kim SY, Park CM: Regulation of leaf senescence by NTL9-mediated osmotic stress signaling in Arabidopsis. Mol Cell 2008, 25(3):438-445

57. Kim JH, Nguyen NH, Jeong CY, Nguyen NT, Hong SW, Lee H: Loss of the R2R3 MYB, AtMyb73, causes hyper-induction of the SOS1 and SOS3 genes in response to high salinity in Arabidopsis. J Plant Physiol 2013, 170(16):1461-1465.

58. Cheng MC, Liao PM, Kuo WW, Lin TP: The arabidopsis ETHYLENE RESPONSE FACTOR1 regulates abiotic stress-responsive gene expression by binding to different cis-acting elements in response to different stress signals. Plant Physiol 2013, 162(3):1566-1582

59. Yang Z, Tian L, Latoszek-Green M, Brown D, Wu K: Arabidopsis ERF4 is a transcriptional repressor capable of modulating ethylene and abscisic acid responses. Plant Mol Biol 2005, 58(4):585-596.

60. Kim MJ, Park MJ, Seo PJ, Song JS, Kim HJ, Park CM: Controlled nuclear import of the transcription factor NTL6 reveals a cytoplasmic role of SnRK2.8 in the drought-stress response. Biochem J 2012, 448(3):353-363.

61. Zhu H, Li GJ, Ding L, Cui X, Berg H, Assmann SM, Xia Y: Arabidopsis extra large G-protein 2 (XLG2) interacts with the Gbeta subunit of heterotrimeric $\mathrm{G}$ protein and functions in disease resistance. Mol Plant 2009, 2(3):513-525.

62. Nakata M, Mitsuda N, Herde M, Koo AJ, Moreno JE, Suzuki K, Howe GA, Ohme-Takagi M: A bHLH-type transcription factor, ABA-INDUCIBLE BHLHTYPE TRANSCRIPTION FACTOR/JA-ASSOCIATED MYC2-LIKE1, acts as a repressor to negatively regulate jasmonate signaling in arabidopsis. Plant Cell 2013, 25(5):1641-1656.
63. Robatzek S, Somssich IE: A new member of the Arabidopsis WRKY transcription factor family, AtWRKY6, is associated with both senescence- and defence-related processes. Plant J 2001, 28(2):123-133.

64. Chen YF, Li LQ, Xu Q, Kong YH, Wang H, Wu WH: The WRKY6 transcription factor modulates PHOSPHATE1 expression in response to low Pi stress in Arabidopsis. Plant Cell 2009, 21(11):3554-3566.

65. Kasajima I, Ide Y, Yokota Hirai M, Fujiwara T: WRKY6 is involved in the response to boron deficiency in Arabidopsis thaliana. Physiol Plant 2010, 139(1):80-92.

66. Frith MC, Fu Y, Yu L, Chen JF, Hansen U, Weng Z: Detection of functional DNA motifs via statistical over-representation. Nucleic Acids Res 2004 32(4):1372-1381.

67. Wingender E, Dietze $P$, Karas H, Knuppel R: TRANSFAC: a database on transcription factors and their DNA binding sites. Nucleic Acids Res 1996, 24(1):238-241.

68. Cheong YH, Chang HS, Gupta R, Wang X, Zhu T, Luan S: Transcriptional profiling reveals novel interactions between wounding, pathogen, abiotic stress, and hormonal responses in Arabidopsis. Plant Physiol 2002, 129(2):661-677.

69. Ghanashyam C, Jain M: Role of auxin-responsive genes in biotic stress responses. Plant Signal Behav 2009, 4(9):846-848.

70. He JX, Gendron JM, Sun Y, Gampala SS, Gendron N, Sun CQ, Wang ZY: BZR1 is a transcriptional repressor with dual roles in brassinosteroid homeostasis and growth responses. Science 2005, 307(5715):1634-1638.

71. Li XP, Tian AG, Luo GZ, Gong ZZ, Zhang JS, Chen SY: Soybean DRE-binding transcription factors that are responsive to abiotic stresses. Theor Appl Genet 2005, 110(8):1355-1362.

72. Shin J, Park E, Choi G: PIF3 regulates anthocyanin biosynthesis in an HY5-dependent manner with both factors directly binding anthocyanin biosynthetic gene promoters in Arabidopsis. Plant J 2007, 49(6):981-994.

73. Solano R, Nieto C, Avila J, Canas L, Diaz I, Paz-Ares J: Dual DNA binding specificity of a petal epidermis-specific MYB transcription factor (MYB. Ph3) from Petunia hybrida. EMBO J 1995, 14(8):1773-1784.

74. Dang HQ, Tran NQ, Tuteja R, Tuteja N: Promoter of a salinity and cold stress-induced MCM6 DNA helicase from pea. Plant Signal Behav 2011, 6(7):1006-1008.

75. Lindermayr C, Sell S, Muller B, Leister D, Durner J: Redox regulation of the NPR1-TGA1 system of Arabidopsis thaliana by nitric oxide. Plant Cell 2010, 22(8):2894-2907.

76. Despres C, Chubak C, Rochon A, Clark R, Bethune T, Desveaux D, Fobert PR: The Arabidopsis NPR1 disease resistance protein is a novel cofactor that confers redox regulation of DNA binding activity to the basic domain/ leucine zipper transcription factor TGA1. Plant Cell 2003, 15(9):2181-2191.

77. Kobayashi Y, Murata M, Minami H, Yamamoto S, Kagaya Y, Hobo T, Yamamoto A, Hattori T: Abscisic acid-activated SNRK2 protein kinases function in the gene-regulation pathway of $A B A$ signal transduction by phosphorylating ABA response element-binding factors. Plant J 2005, 44(6):939-949.

78. Kang JY, Choi HI, Im MY, Kim SY: Arabidopsis basic leucine zipper proteins that mediate stress-responsive abscisic acid signaling. Plant Cell 2002, 14(2):343-357.

79. Sell S, Hehl R: Functional dissection of a small anaerobically induced bZIP transcription factor from tomato. Eur J Biochem 2004, 271(22):4534-4544.

80. Wei W, Huang J, Hao YJ, Zou HF, Wang HW, Zhao JY, Liu XY, Zhang WK, Ma B, Zhang JS, Chen SY: Soybean GmPHD-type transcription regulators improve stress tolerance in transgenic Arabidopsis plants. PLoS One 2009, 4(9):e7209.

81. Dubos C, Stracke R, Grotewold E, Weisshaar B, Martin C, Lepiniec L: MYB transcription factors in Arabidopsis. Trends Plant Sci 2010, 15(10):573-581.

82. Ding Z, Li S, An X, Liu X, Qin H, Wang D: Transgenic expression of MYB15 confers enhanced sensitivity to abscisic acid and improved drought tolerance in Arabidopsis thaliana. J Genet Genomics 2009, 36(1):17-29.

83. Blanchet E, Annicotte JS, Lagarrigue S, Aguilar V, Clape C, Chavey C, Fritz V, Casas F, Apparailly F, Auwerx J, Fajas L: E2F transcription factor-1 regulates oxidative metabolism. Nat Cell Biol 2011, 13(9):1146-1152.

84. Mariconti L, Pellegrini B, Cantoni R, Stevens R, Bergounioux C, Cella R, Albani $D$ : The E2F family of transcription factors from Arabidopsis thaliana. Novel and conserved components of the retinoblastoma/E2F pathway in plants. J Biol Chem 2002, 277(12):9911-9919.

85. Manavella PA, Dezar CA, Ariel FD, Drincovich MF, Chan RL: The sunflower HD-Zip transcription factor HAHB4 is up-regulated in darkness, reducing 
the transcription of photosynthesis-related genes. J Exp Bot 2008, 59(11):3143-3155.

86. Sakuma Y, Liu Q, Dubouzet JG, Abe H, Shinozaki K, Yamaguchi-Shinozaki K: DNA-binding specificity of the ERF/AP2 domain of Arabidopsis DREBs, transcription factors involved in dehydration- and cold-inducible gene expression. Biochem Biophys Res Commun 2002, 290(3):998-1009.

87. Osnato M, Stile MR, Wang Y, Meynard D, Curiale S, Guiderdoni E, Liu Y, Horner DS, Ouwerkerk PB, Pozzi C, Muller KJ, Salamini F, Rossini L: Cross talk between the KNOX and ethylene pathways is mediated by intron-binding transcription factors in barley. Plant Physiol 2010, 154(4):1616-1632

88. Kawaoka A, Kaothien P, Yoshida K, Endo S, Yamada K, Ebinuma H: Functional analysis of tobacco LIM protein Ntlim1 involved in lignin biosynthesis. Plant J 2000, 22(4):289-301.

89. Yang S, Sweetman JP, Amirsadeghi S, Barghchi M, Huttly AK, Chung WI, Twell D: Novel anther-specific myb genes from tobacco as putative regulators of phenylalanine ammonia-lyase expression. Plant Physiol 2001, 126(4):1738-1753.

90. Dixon RA, Paiva NL: Stress-induced phenylpropanoid metabolism. Plant Cell 1995, 7(7):1085-1097.

91. Faria JA, Reis PA, Reis MT, Rosado GL, Pinheiro GL, Mendes GC, Fontes EP: The NAC domain-containing protein, GmNAC6, is a downstream component of the ER stress- and osmotic stress-induced NRP-mediated cell-death signaling pathway. BMC Plant Biol 2011, 11:129.

92. Mukherjee K, Choudhury AR, Gupta B, Gupta S, Sengupta DN: An ABREbinding factor, OSBZ8, is highly expressed in salt tolerant cultivars than in salt sensitive cultivars of indica rice. BMC Plant Biol 2006, 6:18.

93. Grotewold $E_{1}$ Athma P, Peterson T: Alternatively spliced products of the maize $\mathrm{P}$ gene encode proteins with homology to the DNA-binding domain of myb-like transcription factors. Proc Natl Acad Sci U S A 1991, 88(11):4587-4591.

94. Styles ED, Ceska O: Genetic-control of flavonoid synthesis in Maize. Can J Genet Cytol 1977, 19(2):289-302.

95. Woo HR, Kim JH, Kim J, Lee U, Song IJ, Lee HY, Nam HG, Lim PO: The RAV1 transcription factor positively regulates leaf senescence in Arabidopsis. J Exp Bot 2010, 61(14):3947-3957.

96. Le DT, Nishiyama R, Watanabe Y, Mochida K, Yamaguchi-Shinozaki K Shinozaki K, Tran LS: Genome-wide survey and expression analysis of the plant-specific NAC transcription factor family in soybean during development and dehydration stress. DNA Res 2011, 18(4):263-276

97. Reddy AS, Ali GS, Celesnik H, Day IS: Coping with stresses: roles of calcium- and calcium/calmodulin-regulated gene expression. Plant Cell 2011, 23(6):2010-2032

98. Fan W, Dong X: In vivo interaction between NPR1 and transcription factor TGA2 leads to salicylic acid-mediated gene activation in Arabidopsis. Plant Cell 2002, 14(6):1377-1389.

99. Journot-Catalino N, Somssich IE, Roby D, Kroj T: The transcription factors WRKY11 and WRKY17 act as negative regulators of basal resistance in Arabidopsis thaliana. Plant Cell 2006, 18(11):3289-3302.

100. Stein RJ, Waters BM: Use of natural variation reveals core genes in the transcriptome of iron-deficient Arabidopsis thaliana roots. J Exp Bot 2012, 63(2):1039-1055.

101. Waters BM, Mclnturf SA, Stein RJ: Rosette iron deficiency transcript and microRNA profiling reveals links between copper and iron homeostasis in Arabidopsis thaliana. J Exp Bot 2012, 63(16):5903-5918.

102. Buckhout TJ, Yang TJ, Schmidt W: Early iron-deficiency-induced transcriptional changes in Arabidopsis roots as revealed by microarray analyses. BMC Genomics 2009, 10:147.

103. Yang TJ, Lin WD, Schmidt W: Transcriptional profiling of the Arabidopsis iron deficiency response reveals conserved transition metal homeostasis networks. Plant Physiol 2010, 152(4):2130-2141.

104. Hermans C, Vuylsteke M, Coppens F, Craciun A, Inze D, Verbruggen N: Early transcriptomic changes induced by magnesium deficiency in Arabidopsis thaliana reveal the alteration of circadian clock gene expression in roots and the triggering of abscisic acid-responsive genes. New Phytol 2010, 187(1):119-131.

105. Kim SA, Punshon T, Lanzirotti A, Li L, Alonso JM, Ecker JR, Kaplan J, Guerinot ML: Localization of iron in Arabidopsis seed requires the vacuolar membrane transporter VIT1. Science 2006, 314(5803):1295-1298.

106. Rodriguez-Celma J, Pan IC, Li W, Lan P, Buckhout TJ, Schmidt W: The transcriptional response of Arabidopsis leaves to Fe deficiency. Front Plant Sci 2013, 4:276
107. Waters BM, Chu HH, Didonato RJ, Roberts LA, Eisley RB, Lahner B, Salt DE, Walker EL: Mutations in Arabidopsis yellow stripe-like1 and yellow stripe-like3 reveal their roles in metal ion homeostasis and loading of metal ions in seeds. Plant Physiol 2006, 141(4):1446-1458.

108. DiDonato RJ Jr, Roberts LA, Sanderson T, Eisley RB, Walker EL: Arabidopsis Yellow Stripe-Like2 (YSL2): a metal-regulated gene encoding a plasma membrane transporter of nicotianamine-metal complexes. Plant J 2004, 39(3):403-414.

109. Long TA, Tsukagoshi H, Busch W, Lahner B, Salt DE, Benfey PN: The bHLH transcription factor POPEYE regulates response to iron deficiency in Arabidopsis roots. Plant Cell 2010, 22(7):2219-2236.

110. Roppolo D, De Rybel B, Tendon VD, Pfister A, Alassimone J, Vermeer JE, Yamazaki M, Stierhof YD, Beeckman T, Geldner N: A novel protein family mediates Casparian strip formation in the endodermis. Nature 2011, 473(7347):380-383

111. Hosmani PS, Kamiya T, Danku J, Naseer S, Geldner N, Guerinot ML, Salt DE: Dirigent domain-containing protein is part of the machinery required for formation of the lignin-based Casparian strip in the root. PNAS 2013, 110(35):14498-14503.

112. Lee $Y$, Rubio MC, Alassimone J, Geldner N: A mechanism for localized lignin deposition in the endodermis. Cell 2013, 153(2):402-412.

113. Roschzttardtz H, Conejero G, Divol F, Alcon C, Verdeil JL, Curie C, Mari S: New insights into Fe localization in plant tissues. Front Plant Sci 2013, 4:350

114. Schmid NB, Giehl RF, Doll S, Mock HP, Strehmel N, Scheel D, Kong X, Hider RC, von Wiren N: Feruloyl-CoA 6'-Hydroxylase1-dependent coumarins mediate iron acquisition from alkaline substrates in Arabidopsis. Plant Physiol 2014, 164(1):160-172.

115. Rodriguez-Celma J, Lin WD, Fu GM, Abadia J, Lopez-Millan AF, Schmidt W: Mutually exclusive alterations in secondary metabolism are critical for the uptake of insoluble iron compounds by Arabidopsis and Medicago truncatula. Plant Physiol 2013, 162(3):1473-1485.

116. Fourcroy P, Siso-Terraza P, Sudre D, Saviron M, Reyt G, Gaymard F, Abadia A, Abadia J, Alvarez-Fernandez A, Briat JF: Involvement of the ABCG37 transporter in secretion of scopoletin and derivatives by Arabidopsis roots in response to iron deficiency. New Phytol 2014, 201(1):155-167.

117. Garcia MJ, Lucena C, Romera FJ, Alcantara E, Perez-Vicente R: Ethylene and nitric oxide involvement in the up-regulation of key genes related to iron acquisition and homeostasis in Arabidopsis. J Exp Bot 2010, 61(14):3885-3899.

118. Lin Z, Zhong S, Grierson D: Recent advances in ethylene research. J Exp Bot 2009, 60(12):3311-3336.

119. Kieber JJ, Rothenberg M, Roman G, Feldmann KA, Ecker JR: CTR1, a negative regulator of the ethylene response pathway in Arabidopsis, encodes a member of the raf family of protein kinases. Cell 1993, 72(3):427-441

120. Penninckx IA, Eggermont K, Terras FR, Thomma BP, De Samblanx GW Buchala A, Metraux JP, Manners JM, Broekaert WF: Pathogen-induced systemic activation of a plant defensin gene in Arabidopsis follows a salicylic acid-independent pathway. Plant Cell 1996, 8(12):2309-2323.

121. Cooper CE: Nitric oxide and iron proteins. Biochim Biophys Acta 1999 1411(2-3):290-309.

122. Hey SJ, Byrne E, Halford NG: The interface between metabolic and stress signalling. Ann Bot 2010, 105(2):197-203.

123. Gwinn DM, Shackelford DB, Egan DF, Mihaylova MM, Mery A, Vasquez DS, Turk BE, Shaw RJ: AMPK phosphorylation of raptor mediates a metabolic checkpoint. Mol Cell 2008, 30(2):214-226.

124. Henriques R, Magyar Z, Monardes A, Khan S, Zalejski C, Orellana J, Szabados L, de la Torre C, Koncz C, Bogre L: Arabidopsis S6 kinase mutants display chromosome instability and altered RBR1-E2F pathway activity. EMBO J 2010, 29(17):2979-2993.

125. Schroder F, Lisso J, Lange P, Mussig C: The extracellular EXO protein mediates cell expansion in Arabidopsis leaves. BMC Plant Biol 2009, 9:20.

126. Schroder F, Lisso J, Mussig C: EXORDIUM-LIKE1 promotes growth during low carbon availability in Arabidopsis. Plant Physiol 2011, 156(3):1620-1630.

127. Schroder F, Lisso J, Mussig C: Expression pattern and putative function of EXL1 and homologous genes in Arabidopsis. Plant Signal Behav 2012, $7(1): 22-27$.

128. Xiong Y, McCormack M, Li L, Hall Q, Xiang C, Sheen J: Glucose-TOR signalling reprograms the transcriptome and activates meristems. Nature 2013, 496(7444):181-186 
129. Froehlich DM, Fehr WR: Agronomic performance of soybeans with differing levels of iron-deficiency chlorosis on calcareous soil. Crop Sci 1981, 21(3):438-441.

130. Helms TC, Scott RA, Schapaugh WT, Goos RJ, Franzen DW, Schlegel AJ Soybean iron-deficiency chlorosis tolerance and yield decrease on calcareous soils. Agron J 2010, 102(2):492-498.

131. Chaney RLCBA, Bell PF, Angle JS: Detailed method to screen dicot cultivars for resistance to Fe-chlorosis using FeDTPA and biocarbonate in nutrient solutions. J Plant Nutr 1992, 15:2063-2083.

132. Trapnell C, Pachter L, Salzberg SL: TopHat: discovering splice junctions with RNA-Seq. Bioinformatics 2009, 25(9):1105-1111.

133. Li HHB, Wysoker A, Fennell T, Ruan J, Homer N, Marth G, Abecasis G, Durbin R, 1000 Genome Project Data Processing Subgroup: The Sequence alignment/map (SAM) format and SAMtools. Bioinformatics 2009, 25:2078-2079.

134. Morgan $M$, Pages $H$ : Rsamtools: Binary alignment (BAM), variant call (BCF), or tabix file import. $R$ package 2010, version 1(4.3).

135. Lawrence M, Gentleman R, Carey V: rtracklayer: an R package for interfacing with genome browsers. Bioinformatics 2009, 25(14):1841-1842.

136. Lawrence M, Huber W, Pages H, Aboyoun P, Carlson M, Gentleman R, Morgan MT, Carey VJ: Software for computing and annotating genomic ranges. PLoS Comput Biol 2013, 9(8):e1003118.

137. Robinson MD, Smyth GK: Moderated statistical tests for assessing differences in tag abundance. Bioinformatics 2007, 23(21):2881-2887.

138. Robinson MD, Smyth GK: Small-sample estimation of negative binomial dispersion, with applications to SAGE data. Biostatistics 2008, 9(2):321-332.

139. McCarthy DJ, Chen Y, Smyth GK: Differential expression analysis of multifactor RNA-Seq experiments with respect to biological variation. Nucleic Acids Res 2012, 40(10):4288-4297.

140. Berardini TZ, Mundodi S, Reiser L, Huala E, Garcia-Hernandez M, Zhang P, Mueller LA, Yoon J, Doyle A, Lander G, Moseyko N, Yoo D, Xu I, Zoeckler B, Montoya M, Miller N, Weems D, Rhee SY: Functional annotation of the Arabidopsis genome using controlled vocabularies. Plant Physiol 2004, 135(2):745-755.

141. Grossmann S, Bauer S, Robinson PN, Vingron M: Improved detection of overrepresentation of Gene-Ontology annotations with parent child analysis. Bioinformatics 2007, 23(22):3024-3031.

142. Fisher RA: The Design of Experiments. 8th edition. Edinburgh: London: Oliver \& Boyd; 1966.

143. Bonferroni CE: III Calcolo delle assicurazioni su gruppi di teste. Studi in Onore del Professore Salvatore Ortu Carboni 1935, 13-60.

doi:10.1186/1471-2164-15-702

Cite this article as: Moran Lauter et al:: Identification of candidate genes involved in early iron deficiency chlorosis signaling in soybean (Glycine max) roots and leaves. BMC Genomics 2014 15:702.

\section{Submit your next manuscript to BioMed Central and take full advantage of:}

- Convenient online submission

- Thorough peer review

- No space constraints or color figure charges

- Immediate publication on acceptance

- Inclusion in PubMed, CAS, Scopus and Google Scholar

- Research which is freely available for redistribution 